\title{
Numerical modeling on air injection in a light oil reservoir: Recovery mechanism and scheme optimization
}

\author{
Hu Jia* and James J. Sheng \\ State Key Laboratory of Oil and Gas Reservoir Geology and Exploitation, Southwest Petroleum University, \\ Chengdu, Sichuan 610500, China, and Bob L. Herd Department of Petroleum Engineering, Texas Tech University, \\ Lubbock, TX 79409, USA \\ *Corresponding author: hu.jia@ttu.edu; jiahuswpu@swpu.edu.cn
}

\section{Summary}

Air injection in light oil reservoirs is a promising enhanced oil recovery (EOR) method because of its wide availability, low cost, and ability to stimulate subterranean oil combustion. However, oil recovery mechanisms and physical processes for air injection in conventional light oil reservoirs are still not well understood. An improved understanding of air injection mechanism in conventional light oil reservoirs is provided in this paper. We use the reservoir simulation approach to study air injection in a light oil reservoir. Effects of $\mathrm{O}_{2}$ mole concentration, activation energy, intake air temperature, geological structure and development scheme on the well performance of air injection are examined. The driving mechanism of thermal effect is revealed through the observation of oil rate fluctuating and dynamic temperature distribution. We present the evidence of the "bulldozing effect (or pore blocking)" for air injection in a light oil reservoir which shows the sudden decrease of gas relative permeability. The effect has the potential of re-directing gas flow to improve sweep efficiency. Analysis of influence factors from this work indicates that the oil recovery factor is sensitive to $\mathrm{O}_{2}$ content in air and geological structure of the reservoir. The performance with gas injected updip is better than that downdip. It is insensitive to intake air temperature or activation energy in the reaction scheme favoring a generation of more $\mathrm{H}_{2} \mathrm{O}$, insoluble $\mathrm{CO}$ and $\mathrm{CH}_{4}$.

Keywords: air injection; light oil; thermal effect; bulldozing; pore blocking

\section{Introduction}

Historically, successful light oil air injection projects mainly include Buffalo, Medicine Pole Hills Unit (MPHU), Horse Creek, Coral Creek and Hackberry fields [1-5]. Field experiences and project design that indicate spontaneous low temperature oxidation (LTO) can lead to in-situ combustion, which may occur in fields with relatively high reservoir temperature 194 - 
$248^{\circ} \mathrm{F}\left(90-120^{\circ} \mathrm{C}\right)$ and pressures [6-8]. The preexisting evidence from the Buffalo Red River Unit (BRRU) and South Buffalo Red River Unit (SBRRU) in the Buffalo field indicates that oil is actually burning and suggests that the combustion front has a favorable impact on the production performance of the oil field [9]. A stable propagation of combustion front can provide more benefits of the thermal recovery process for air injection both in light oil and heavy oil reservoirs [10-11]. Heavy oil is known to be rich in heavier unsaturates such as resins and asphaltenes[12]. These components mainly dominate oxygen addition reaction in LTO to generate various oxygenated hydrocarbons, such as alcohols, aldehydes, hydroperoxides, ketones, carboxylic acids and water [13,14]. Application of in-situ combustion in heavy oil reservoirs sometimes requires an ignition operation to initiate it and create the heat wave, while air injection in light oil does not [15]. The reported main recovery mechanisms of air injection in light oil are summarized as: 1) improvement of sweep efficiency due to flue-gas sweep; 2) rapid re-pressurization of reservoirs; 3) light components extracting for subsequent liquid nature gas flooding; 4) oil swelling by flue-gas dissolution; 5) the potential of miscible flooding; 6) the creation of thermally generated microfractures in the reservoir; and 7) crude oil viscosity reduction by thermal effects [16-22].

The above mechanisms are mainly drawn from theoretical hypothesis, lab experiments, and field performance. Over the years, air injection in light oil has been simply modeled as gas flood, giving little credit to combustion as a drive mechanism [8, 23-25]. Jia et al [26] derived a mathematical model to investigate how thermal effects influence production performance by qualitative analysis. They concluded that such methods as reducing well spacing and extending air injection cycle should be taken into consideration to achieve a high oil recovery factor contributed by thermal effects. Besides, field experience and laboratory testing also concluded that air injection in a light oil reservoir is beneficial both from primary gas flooding effects and secondary thermal driving after a certain pore volume of air is injected [27]. Additionally, the "bulldozing effect" (or pore blocking) feature is assumed to occur in light oil air injection based on several hypotheses [28]. However, the terminology is mainly used for air injection in heavy oil reservoirs for in-situ combustion [29]. Hence, further investigation is needed to prove 
whether "bulldozing effects" (or pore blocking) really exists during air injection for light oil. Ref [28] proposed that the "bulldozing effect" is treated as the drive mechanism of thermal effects for air injection in light oil reservoirs, and people start to recognize that the thermal effects drive should be a main recovery mechanism for air injection, but no simulation work to visualize this process and how it works has been done.

To the best of our knowledge, the comprehensive study on the recovery mechanisms of air injection in light oil works is poor, especially for the thermal effects drive from the aspect of reservoir simulation interpretation. Misunderstanding of air injection mechanism would seriously lead to the failure of project design. The numerical modelling of the field performance of air injection projects still face challenges due to the sufficiently complexity of oxidation reactions [28]. But we have no alternative except for this tool for predicting the field performance of air injection. No matter how strong the numerical simulators are, human experience is vital for designing a reasonable reaction scheme as well as operating the process based on laboratory testing results. Hence, we can interpret the recovery mechanism of air injection from simulation results in a reasonable way for better guiding field design.

The aim of this work is to visualize the main recovery mechanisms of air injection in light oil reservoir as well as to prove the thermal effect and pore blocking phenomenon hypothesis by a numerical simulation approach. The basic model is first calibrated from the simulation results of air injection in a North Sea light oil field [30-31]. It must be pointed out that the calibrated model was well upscaled from combustion tube experiments, while some important findings were still not revealed due to the limited knowledge of recognizing air injection mechanisms at that time as well as serious numerical instability of the old version of the simulator. The rest of this paper is organized as follows. Section 2 describes reservoir simulation model set-up and methodologies. Section 3 introduces fluid properties and reaction schemes. Section 4 initiates theoretical analysis on air injection mechanism and scheme optimization. Some highlights are summarized in Section 5. This work can provide a better understanding of the air injection mechanism in light oil reservoirs with the aid of numerical simulation, which can be extended to evaluate air injection in tight oil reservoirs in North 
America such as Eagle Ford shale of West Texas, Bakken shale of North Dakota, and Marcellus shale of Pennsylvania with high reservoir temperatures between $168-255^{\circ} \mathrm{F}$ and API gravities greater than $40^{\circ}[32-34]$.

\section{Reservoir simulation model}

A 3-D Cartesian grid of $22 \times 9 \times 5$ with 990 active blocks is used in this field scale model as show in Figure 1. The total grid block size is set to $2742 \mathrm{ft} \times 865 \mathrm{ft} \times 175 \mathrm{ft}$ in $\mathrm{x}, \mathrm{y}, \mathrm{z}$ directions, respectively. Reservoir properties are based on the actual data in the North Sea oil field [31]. The initial reservoir pressure of $6440 \mathrm{psi}$ and temperature of $210^{\circ} \mathrm{F}$ are used. The reservoir top depth TVD is $8205 \mathrm{ft}$ with a dip angle of around $15^{\circ}$. The calculation of the geological structure is based on the variation of the top depths in the grid columns. In this model, the depth to the top of each grid column is set from maximum $8620 \mathrm{ft}$ to minimum $8200 \mathrm{ft}$ with $20 \mathrm{ft}$ gradient. The reservoir permeability is $1100 \mathrm{md}$ and $1300 \mathrm{md}$, respectively, for the upper three layers and the bottom two layers. The porosity and initial oil saturation are 0.19 and 0.55 for all the layers. The perforated horizontal injection well (Well 2) and production well (Well 1) are located in the downdip and updip, respectively, in the base case.

The software used for numerical simulations was CMG-STARS (version 2014) with the non-isothermal module. A typical thermal simulator solves mass and heat balance equations below $[13,35,36]$.

The conservation equation of flowing component $i$ is

$$
\begin{gathered}
\frac{\partial}{\partial x}\left[V_{f}\left(\rho_{w} S_{w} w_{i}+\rho_{o} S_{o} x_{i}+\rho_{g} S_{g} y_{i}\right)\right]=\sum_{k=1}^{n_{f}}\left[T_{w} \rho_{w} w_{i} \Delta \phi_{w}+T_{o} \rho_{o} x_{i} \Delta \phi_{o}+T_{g} \rho_{g} y_{i} \Delta \phi_{g}\right]+ \\
V \sum_{k=1}^{n_{r}}\left(s_{k i}^{\prime}-s_{k i}\right) r_{k}+\sigma_{i w} \sum_{k=1}^{n_{f}} \rho_{w} q a q_{w k}+\rho_{w} q_{w} w_{i}+\rho_{o} q_{o} x_{i}+\rho_{g} q_{g} y_{i}[\text { well layer } k]
\end{gathered}
$$

Where $V_{f}$ is volume of fluid phases added together, $\mathrm{V}$ is total region volume. $\rho$ is phase density, $S$ is phase saturation, $\mathrm{T}$ is phase temperature and $\Delta \phi$ is potential gradient of phase. $q a q_{w k}$ is a volumetric water flow rate through a block face $\mathrm{k}$ to/from the adjacent aquifer, $q$ is volumetric flow rate of phase. $n_{f}$ is the number of neighboring regions or grid block faces. $n_{r}$ is the number of reactions. Superscript "w, o, g" is water, oil and gas phase, respectively. 
$w_{i}, x_{i}$ and $y_{i}$ is related to $\mathrm{K}$-values for each component $\mathrm{i}$.

The conservation equation of solid component $i$ is given as

$$
\frac{\partial}{\partial t}\left[V_{v} c_{i}\right]=V \sum_{k=1}^{n_{r}}\left(s_{k i}^{\prime}-s_{k i}\right) r_{k}
$$

Where $V_{v}$ is void volume, $c_{i}$ is mole concentration of component $\mathrm{i}$ in $V_{v}, s_{k i}^{\prime}$ is the product stoichiometric coefficient of component $\mathrm{i}$ in reaction $\mathrm{k}, s_{k i}$ is the reactant stoichiometric coefficient of component $\mathrm{i}$ in reaction $\mathrm{k}$ and $r_{k}$ is the volumetric rate of reaction $\mathrm{k}$, calculated from a model for reaction kinetics.

The conservation equation of energy can be written as

$$
\begin{array}{r}
\frac{\partial}{\partial x}\left[V_{f}\left(\rho_{w} S_{w} U_{w}+\rho_{o} S_{o} U_{o}+\rho_{g} S_{g} U_{g}\right)+V_{v} c_{s} U_{s}+V_{r} U_{r}\right]= \\
\sum_{k=1}^{n_{f}}\left[T_{w} \rho_{w} H_{w} \Delta \phi_{w}+T_{o} \rho_{o} H_{o} \Delta \phi_{o}+T_{g} \rho_{g} H_{g} \Delta \phi_{g}\right]+\sum_{k=1}^{n_{f}} K \Delta T+\rho_{w} q_{w} H_{w}+\rho_{o} q_{o} H_{o}+ \\
\rho_{g} q_{g} H_{g}[\text { well layer } k]+V \sum_{k=1}^{n_{r}} H_{r k} r_{k}+H L_{k}+H L_{V}+H L_{c}+\sum_{k=1}^{n_{f}}\left(H A_{C V}+H A_{C D}\right)_{k}
\end{array}
$$

Where $\mathrm{U}$ is the internal energies as a function of temperature and phase, $\mathrm{c}$ is phase concentration, $\mathrm{H}$ is the enthalpy of phase, $\mathrm{H}_{\mathrm{rk}}$ is the enthalpy of reaction $\mathrm{k}, \mathrm{HL}_{\mathrm{k}}$ is the rate of heat transfer to the region of interest through the block face numbering $\mathrm{k}$ from the adjacent formation, $\mathrm{HL}_{\mathrm{v}}$ is the rate of heat transfer calculated from a convective model, $\mathrm{HL}_{\mathrm{c}}$ represents a constant heat transfer model, $\mathrm{HA}_{\mathrm{CV}}$ is a rate of heat transferred by convection to/from the adjacent aquifer, and $\mathrm{HA}_{\mathrm{CD}}$ is a rate of heat transferred by conduction to/from the adjacent aquifer. Superscript "s, r" is solid phase and rock, respectively.

\section{Fluid properties and reaction schemes}

\subsection{Fluid properties}

The North Sea light crude oil is used in the simulation model. The water saturation is 0.45 , oil viscosity is $0.55 \mathrm{cp}$ and oil gravity is $40.2^{\circ} \mathrm{API}$ at the initial reservoir conditions. It is assumed that the crude oil of the North Sea can be classified into different pseudo components: $\mathrm{C}_{21+}$, $\mathrm{C}_{11-} \mathrm{C}_{20}, \mathrm{C}_{6-} \mathrm{C}_{10}, \mathrm{C}_{2-} \mathrm{C}_{5}$ and $\mathrm{CH}_{4}$. The pseudo components and properties are calculated through the Peng-Robinson equation-of-state (EOS) method by the use of the CMG-WinProp Package. These compositional data can represent the actual petroleum fluid for the study. Additionally, 
another six components including $\mathrm{H}_{2} \mathrm{O}, \mathrm{CO}_{2}, \mathrm{~N}_{2} \mathrm{O}_{2}, \mathrm{CO}$ and Coke (solid) added for fulfilling air injection simulation. The properties of the total eleven pseudo compounders are summarized in Table 1 in detail [31]. Phase behavior can be estimated with Gas-liquid $\mathrm{K}$-values, which are functions of pressure, temperature, and composition that can be obtained through CMG STARS-WinProp PVT module [37].

\subsection{Reaction schemes}

The oxidation and combustion process of crude oil is rather complex and hundreds of chemical reactions occur over different temperature ranges. Zelenko and Solignac [38] indicated that a single-reaction combustion model will not represent the complex in-situ combustion process adequately, and Ambastha and Kumar [39] found that a four-reaction model gave a much higher cumulative oil production than that of a single-reaction model. Ren et al. [40] suggested that the complete reaction scheme is very complex and may involve hundreds of intermediate products and reactions. However, in general, it can be described by two reactions: oxidation, which consumes oxygen and generates oxygenated compounds; and decomposition, which produces carbon oxides. Dembla Dhiraj [41] used two reactions of cracking and burning for light components, and one reaction for coke burning to model air injection in the West Texas light oil reservoir. de Zwart et al. [42] proposed a new reaction model that consists of one crack reaction and three combustion reactions. Of these combustion reactions, one describes the combustion of coke and the other two reactions describe the combustion of the light and medium components of crude oil. Jia et al. [43] used five reaction schemes that can govern crude oil cracking, gas combustion, and coke combustion for his air injection simulation study in light oil reservoirs with and without water flooded. A recent study stated that seven reaction schemes composed of four combustion reactions, two cracking reactions and one oxygen addition reaction, can successfully reproduce the oxidation/combustion behavior of two light oils for the air injection simulation study [44].

Hence, how to set up a reasonable reaction scheme is still controversial. Up to now, there are no uniform reaction schemes to govern the complex processes. There are no unsaturated 
data available for the North Sea light crude oil, which mainly dominate oxygen addition reaction in LTO. Theoretically, the unsaturates should not be higher for such a very light oil. Besides, the North Sea oil field with the high temperature of $210{ }^{\circ} \mathrm{F}$ has the potential to quickly promote spontaneous ignition. Hence, oxygen addition reaction is not included for the target light oil. In this study, ten reactions are incorporated, which are composed of three cracking reactions and seven combustion reactions as shown below [31].

Two cracking reactions for heavy components:

$$
\begin{aligned}
& \mathrm{C}_{21+} \rightarrow 7.423 \mathrm{CH}_{4}+30.927 \text { Coke } \\
& \mathrm{C}_{21+} \rightarrow 5.213 \mathrm{C}_{2-} \mathrm{C}_{5}+21.674 \text { Coke }
\end{aligned}
$$

One cracking for medium components:

$$
\mathrm{C}_{11-} \mathrm{C}_{20} \rightarrow 3.354 \mathrm{CH}_{4}+11.474 \text { Coke }
$$

One burning for heavy components:

$$
\mathrm{C}_{21}++38.969 \mathrm{O}_{2} \rightarrow 39.287 \mathrm{H}_{2} \mathrm{O}+38.51 \mathrm{CO}+\text { Energy }
$$

Two burning reactions for medium components:

$$
\begin{aligned}
& \mathrm{C}_{11-} \mathrm{C}_{20}+15.358 \mathrm{O}_{2} \rightarrow 15.888 \mathrm{H}_{2} \mathrm{O}+14.829 \mathrm{CO}+\text { Energy } \\
& \mathrm{C}_{6-} \mathrm{C}_{10}+7.624 \mathrm{O}_{2} \rightarrow 8.115 \mathrm{H}_{2} \mathrm{O}+7.152 \mathrm{CO}+\text { Energy }
\end{aligned}
$$

One burning for light components:

$$
\mathrm{C}_{2}-\mathrm{C}_{5}+3.734 \mathrm{O}_{2} \rightarrow 4.268 \mathrm{H}_{2} \mathrm{O}+3.199 \mathrm{CO}+\text { Energy }
$$

One Coke burning:

$$
\text { Coke }+1.400 \mathrm{O}_{2} \rightarrow 0.800 \mathrm{H}_{2} \mathrm{O}+\mathrm{CO}_{2}+\text { Energy }
$$

One $\mathrm{CH}_{4}$ burning:

$$
\mathrm{CH}_{4}+1.500 \mathrm{O}_{2} \rightarrow 2 \mathrm{H}_{2} \mathrm{O}+\mathrm{CO}+\text { Energy }
$$

One $\mathrm{CO}$ burning:

$$
\mathrm{CO}+0.500 \mathrm{O}_{2} \rightarrow \mathrm{CO}_{2}+\text { Energy }
$$

Kinetic parameters, including frequency factor, activation energy, and enthalpy are based on the published work [31]. Reaction rate $r_{k}$ for each scheme is written as follow [36].

$$
r_{k}=r_{r k} * \exp \left(-\frac{E_{a k}}{R T}\right) * \prod_{i=1}^{n_{c}} C_{i}^{e_{k}}
$$

Where $r_{r k}$ is Arrhenius constant, frequency factor or pre-exponential factor, $E_{a k}$ is activation energy, $\mathrm{R}$ is universal gas constant, $\mathrm{T}$ is region temperature, $C_{i}$ is concentration factor contributed by the reacting component $\mathrm{i}$ and $e_{k}$ is reaction order related to component $\mathrm{i}$.

\section{Results and discussions}




\subsection{Base case}

To predict performance, it is very important to validate the model to guarantee a high reliability of simulation results. For the base case, the gas injector is constrained with the maximum injection rate of $65000 \mathrm{MSCF} /$ day and the maximum bottom-hole pressure of $6,800 \mathrm{psi}$, while the maximum liquid rate of $2300 \mathrm{bbl} / \mathrm{day}$ and the minimum bottom-hole pressure of $5500 \mathrm{psi}$ are used for producer well constraints. Figure 2 shows that oil recovery factor and oil rate after 10 years of air injection for the base case with total 990 grids is $53.99 \%$ and $1152 \mathrm{bbl} / \mathrm{day}$, respectively. The recovery performance is well matches with the simulation results of $54.20 \%$ oil recovery factor and around $1200 \mathrm{bbl} /$ day oil rate after 10 years of air injection presented by Tingas [31]. Hence, the calibrated reservoir model can be used as a base case to further investigate the EOR mechanism of air injection in light oil reservoirs. A study of grid resolution is an important step when modeling air injection. Keeping the total grid block size same as those in the base case, Figure 2 presents the results of a sensitivity study on grid resolution effect, showing that grid size does not significantly affect well production performance.

The oil rate in the last 4 years of injection can be classified into three scenarios of "decline," "stable," and "fluctuate." The smooth rate decline and temporary stability is an indication of conventional gas injection in a later stage, while the subsequent fluctuations should be the indication of "thermal effect" of air injection. The variation of pressure and temperature change caused by the thermal effect can greatly affect components of K-values, resulting in these fluctuations. The stable stage of oil rate acts as the premonition of thermal effect gradually approaching the production well. We can see that the oil rate only steadily decreases along with several peaks after 8 years of air injection. This is also consistent with the thermal front moving scenario as shown in Figure 3, exhibiting that thermal front breaking through the production well at around 7.5 years after a total of 0.75 pore volume air is injected, while the contribution of thermal effect on oil recovery performance starts to dominate. This is slightly different from Ref [27] using theoretical analysis and experimental tests to conclude that thermal effect becomes the main driving mechanism after 1.0 pore volume of air is 
injected into the reservoir. It suggests that thermal effect has the potential to recovery additional oil after gas breakthrough.

However, the present simulation work and previous inferences can help us better understand the EOR mechanism of air injection in light oil reservoirs. Figure 3 shows that thermal effect can sweep almost the whole reservoir between the two wells with time pass, which may be responsible for the favorable production performance without a direct rate decline in a later stage. Hence, air injection in light oil reservoirs may combine the benefits of $\mathrm{N}_{2}, \mathrm{CO}_{2}$, fuel gas, and thermal effect (thermal driving). Among them, thermal effect only dominates the recovery mechanism in later development periods; hence, enhancing the thermal conductivity of reservoirs is desirable to benefit the thermal effect. Besides, reducing well spacing or extending the air injection cycle is also helpful to oil recovery increments contributed by the thermal effect in advance as proposed by Jia et al. [26]. Most people would disregard the potential benefits of thermal effects if the air injection scheme is very short. This will seriously lead to the misunderstanding of the air injection recovery mechanism as well as project design.

Figure 4 displays the variation of crude oil viscosity at different times, showing that crude oil viscosity decreases with consecutive air injection and increases in some parts of the reservoir with a maximum value of $0.67 \mathrm{cp}$. However, the reduction of crude oil viscosity is not significant for this light crude oil. The slight increase of crude oil viscosity would be an indication of the LTO operating mode, especially away from the injector well. Figure 5 presents the gas relative permeability data along the axis between the gas injector and the producer. The location of selected grids is shown in Figure 6. It exhibits gas relative permeability in all grids initially increasing due to the decreasing of liquid saturation with gas flooding. It is then followed by a sudden decrease, showing the pore block mechanism caused by the rapid mobilization of oil into the downstream pores. Some people tend to use the term "bulldozing effect" to describe the hypothesis [28]. Temporary pore blocking can redirect gas flow, which can improve volumetric sweep efficiency. Moreover, it has the potential of delaying gas breakthrough due to this gas moving frontal "self-adjustment." To the best of our 
knowledge, such complex processes remain as a hypothesis for heavy oil in-situ combustion while not given an appropriate interpretation for light oil combustion. In fact, air injection in the Liaohe light oil field, China, is a good example for proving the pore block mechanism. Pilot tests of various gases $\left(\mathrm{N}_{2}, \mathrm{CO}_{2}\right.$ and air) for injection in the Liaohe light oil field shows that among other gas floodings, gas breakthrough is obviously delayed in the air injection process, indicating favorable gas flow self-adjustment* (according to the discussion with Petroleum Engineers in Liaohe oil field, CNPC, China). Hence, the present work can help us further understand the physical process of air injection with the aid of the simulation approach.

Figure 7 shows that no $\mathrm{O}_{2}$ is produced until about 8 years of air injection. After that, $\mathrm{O}_{2}$ concentration sharply increases to $5 \mathrm{~mol} \%$ in the 8.5 year, followed by a smooth increase to the end of injection with a total of $11.8 \mathrm{~mol} \% \mathrm{O}_{2}$ in the effluent gases. The bottom-hole temperature of the producer well skyrockets to $517^{\circ} \mathrm{F}$ when $\mathrm{O}_{2}$ content increases abruptly. For safety consideration, $\mathrm{O}_{2}$ concentration produced in the well should be lower than 3-5 mol\% [16]. Hence, it is suggested to shut off the injection well at the 8.5-year mark. Hughes and Sarma [18] stated that the potential of recoverable crude oil by thermal effect drive is limited after $\mathrm{O}_{2}$ breakthrough occurs. But this may be not true in all the cases, as we found that oil is still being produced after $\mathrm{O}_{2}$ breakthrough. Before $\mathrm{O}_{2}$ breakthrough, a flat GOR of 6 MSCF/STB is exhibited, indicating the favorable combustion phenomenon [9]. Related to the "pore blocking" effect, the fast mobilization of liquid does not allow the gas phase dominate the flow pathway. GOR sharply increases with many fluctuations after $\mathrm{O}_{2}$ breakthrough as shown in Figure 7, implying unfavorable combustion due to the reduction of available fuel. This will damage production performance contributed by thermal effects, which can be expressed by a steady decrease of oil rate along with the reservoir temperature slowing down as shown in Figures 2 and 3. High GOR will bring out some issues such as emulsions, corrosion and gas interference. Hence, shutoff gas injector or producer in early time is needed when $\mathrm{O}_{2}$ breakthrough is detected.

\subsection{Effect of $\mathrm{O}_{2}$ concentration}


In subsequent sections, we only reduced the air injection rate to the maximum value of 4800 $\mathrm{MSCF} /$ day as the constraint to avoid early gas breakthrough. No adjustments were made forthe other constraints in the base case, unless otherwise indicated. The injection scheme extends to 15 years to further investigate the production performance of air injection.

Figure 8 shows that the ultimate oil recovery factors are $43.70 \%, 45.90 \%, 50.55 \%$, $53.46 \%, 54.76 \%$, and $55.29 \%$ for air injection with $0 \%$ ( $\mathrm{N}_{2}$ flooding), $10 \%, 20 \%, 30 \%, 40 \%$ and $50 \mathrm{~mol} \%$ content $\mathrm{O}_{2}$, respectively. The oil recovery factor is increased with the increase of $\mathrm{O}_{2}$ concentration, as we expected. This is because the prevalence of thermal effect plays an important role on production performance for high $\mathrm{O}_{2}$ content air injection in later stages. This is verified by several fluctuations in oil rate curves in later stages as shown in Figure 9. Besides, it is found that oil rate for high $\mathrm{O}_{2}$ content air injection quickly decreases in later stages. The early $\mathrm{O}_{2}$ breakthrough for high $\mathrm{O}_{2}$ content air injection is responsible for these variations. This is verified in produced $\mathrm{O}_{2}$ content curves as shown in Figure 10. However, oil rate is increased with the decrease of $\mathrm{O}_{2}$ concentration in the first 5 years. For instance, $\mathrm{N}_{2}$ flooding provides the highest oil rate in this stage. In addition, the oil recovery factor increment decreases with the continuous increase of $\mathrm{O}_{2}$ content from 30 to $50 \mathrm{~mol} \%$. This is because of the nature of oil solubility $\mathrm{N}_{2}$ in low oxygen content air that brings out more expansion of crude oil for oil recovery improvement. High $\mathrm{O}_{2}$ content air injection may lose some potential benefits of fuel gas flooding due to the low content oil solubility $\mathrm{N}_{2}$ in this situation.

The dynamic gas relative permeability data in the representative grids for air injection (20 mol\% $\mathrm{O}_{2}$ ) and $\mathrm{N}_{2}$ flooding are presented in Figures 11 and 12. The "pore plugging" effect is observed from the sudden decrease of gas relative permeability for the air injection scenario as we expected, while no indication of the "pore plugging" effect is exhibited for $\mathrm{N}_{2}$ flooding. Gas relative permeability only smoothly increases with the continuous nitrogen injection, as shown in Figure 12. Hence, it further demonstrates that air injection is a complex recovery process quite different from simple nitrogen or fuel gas flooding. $\mathrm{O}_{2}$ breakthrough is also observed in these simulations. Figure 10 shows that $\mathrm{O}_{2}$ content in the production well at the 
end of simulation is $6 \%, 16 \%$, and $22 \mathrm{~mol} \%$, respectively for $30 \%, 40 \%$, and $50 \mathrm{~mol} \% \mathrm{O}_{2}$ content air injection scenarios, while no $\mathrm{O}_{2}$ is observed for air injection with $\mathrm{O}_{2}$ content below $30 \mathrm{~mol} \%$. The low $\mathrm{O}_{2}$ content of air injection can bring out a favorable $\mathrm{O}_{2}$ breakthrough delay, while it will restrict the contribution of thermal effect on oil recovery due to the lowered combustion temperature in the reservoir. Once $\mathrm{O}_{2}$ breakthrough occurs, $\mathrm{O}_{2}$ concentration in the production well will skyrocket to a high value in a short time. Hence, combining with low $\mathrm{O}_{2}$ and rich $\mathrm{O}_{2}$ content, the air injection strategy in the pilot test should be desirable to achieve the role of favorable thermal effects as well as $\mathrm{O}_{2}$ breakthrough delay. $\mathrm{O}_{2}$ concentration monitoring is still a key issue for air injection operating in the well site both from the standpoint of safety consideration and for recognizing the crude oil oxidation mode.

The average reservoir temperatures of different air injection scenarios are displayed in Figure 13. For air injection with $0 \%, 10 \%, 20 \%, 30 \%, 40 \%$, and $50 \mathrm{~mol} \%$ content $\mathrm{O}_{2}$, the final average reservoir temperatures are 210.91, 261.93, 307.98, 336.18, 354.64 and $370.94{ }^{\circ} \mathrm{F}$, respectively, which are increased with the increase of $\mathrm{O}_{2}$ concentration. While the generated large amount of heat at high $\mathrm{O}_{2}$ concentration would not play an efficient role in the initial stage of air injection; only a simple $\mathrm{N}_{2}$ or fuel gas flooding is prevailing in this situation. It further proves that air injection in the early stage more likes a conventional gas flooding, the benefits of thermal effect drive is expected to show only after large amount of air injected. Hence, low $\mathrm{O}_{2}$ content air injection should be an alternative strategy if the designed air injection pore volume is not large.

\subsection{Effect of activation energy}

Kinetic parameters in each reaction scheme dominate the cracking and combustion rate as well as heat release. Choosing a reasonable $E_{a k}$ is very important for thermal recovery simulation study. Up to now, various thermal analysis methods, such as TGA/DSC/ARC and combustion tube, have been widely used to calculate $E_{a k}$ of crude oil for simulation work. In this study, the effect of $E_{a k}$ in each reaction on the oil recovery factor is investigated and the main results are summarized in Table 2 in detail. The study shows that the variation of the oil recovery factor affected by $E_{a k}$ in different reactions can be classified into three groups: (1) 
the oil recovery factor is increased with the increase of $E_{a k}$ for reactions $\mathbf{1}, \mathbf{4 , 5}$ and 7. (2) The oil recovery factor is increased with the decrease of $E_{a k}$ for reactions 2 and 10. (3) The oil recovery factor is not sensitive with the variation of $E_{a k}$ for reactions $3,6,8$ and 9 . Counterintuitively, the lowered $E_{a k}$ should provide a high oil recover factor due to the enhanced reaction activity. However, the complexity of crude oil oxidation and combustion processes increases the difficulty of understanding the air injection mechanism. In this case, the following reasonable explanations can be drawn: if the decreased $E_{a k}$ favors to generate more $\mathrm{C}_{2}-\mathrm{C}_{5}$ and $\mathrm{CO}_{2}$ should be benefitial for oil recovery increment due to the potential miscibility behavior of these components. While in favor of producing more $\mathrm{H}_{2} \mathrm{O}$, insoluble $\mathrm{CO}$ and $\mathrm{CH}_{4}$ at low $E_{a k}$ in a reaction scheme are detrimental, or at least do not show a positive effect for the oil recovery factor. The phenomenon is similar to the combustion tube result from Gates and Ramey [45], indicating that high gas and water saturations may result in a serious lag in oil recovery. Our simulation results could be served as an appropriate explanation to clarify the mechanism of previous experiment observation. Hence, a reasonable reaction scheme design is of great importance for better modeling the air injection process. Hence, a detailed of the effluent gas and crude oil composition is needed to investigate the effect of kinetic parameters.

\subsection{Effect of intake air temperature}

For intake air with temperatures of $100,150,200$, and $250{ }^{\circ} \mathrm{F}$, the oil recovery factor is $50.10 \%, 50.33 \%, 50.47 \%$, and $50.55 \%$, respectively, at the end of simulation as shown in

Figure 14. The oil recovery factors for the intake air with different temperatures does not show obvious variation. Increasing intake air temperature only shortens the ignition time of subterranean crude oil, but not seriously affecting heat release. When spontaneous ignition occurs for the three injection scenarios, the slightly viscosity reduction of this light crude oil in later stages would occur due to thermal effects. Hence, the viscosity reduction of light crude oil that is less important should explain the insignificant oil recovery improvement for intake air with higher temperatures. Injecting high temperature air is not needed, providing subterranean crude oil could be ignited. 


\subsection{Effect of geological structure}

In this scenario, air injection is initiated respectively from downdip and updip locations to investigate the effect of geological structure on production performance while keeping the other parameters the same as those in the base case. The two wells are respectively corresponding to well 1 and well 2 in Figure 1. The oil recovery factor at 15 years of air injection is $50.55 \%$ and $39.80 \%$, respectively, for updip and downdip injection scenarios, as shown in Figure 15. The simulation results of dynamic distributions of gas and water saturations are presented in Figures 16 and 17. The poor oil recovery factor of air injection from downdip is related to early gas breakthrough. However, this gas override in the early period of around 2.5 years provides a higher recovery factor than that by the air injection from updip. However, air injection from updip can better mitigate gas override to avoid early gas breakthrough as well as delay bottom water coning as shown in Figures 16 and 17. Hence, implementing air injection from the updip reservoir is more favorable for achieving high production performance.

\subsection{Scheme Optimization}

In order to optimize the air injection scheme in the pilot test, we compared different cases with and without water flooding. Directly implementing depletion combined with air injection is served as the base case. A minimum bottom-hole pressure of 3500 psi for producer and the maximum water injection rate of $3000 \mathrm{bbl} / \mathrm{day}$ for injector are used as constraints in this scenario, while keeping the other constraints the same as those in the base case. Figure 18 shows that the oil recovery factor at the end of simulation is $60.55 \%, 58.11 \%, 55.15 \%, 52.14 \%$, and $49.05 \%$ for these scenarios: (1) depletion (2 yrs) plus air injection, (2) depletion (2 yrs), followed by water flood (1 yr) and air injection, (3) depletion (2 yrs) followed by water flood (2 yrs) and air injection, (4) depletion (2 yrs) followed by water flood (3 yrs) and air injection and (5) depletion (2 yrs) followed by water flood (4 yrs) and air injection, respectively. It appears that the development scheme of primary depletion plus air injection is desirable fora maximum oil recovery factor. Water cut with time for all the cases are displayed in Figure 19. 
The figure indicates that the maximum water cut is $61.47 \%, 65.77 \%, 87.90 \%$, and $93.20 \%$ after 1 yr, 2 yrs, 3 yrs, and 4 yrs of water flood plus a short time air injection, respectively. It is then followed by a rapid decrease in water cut with the continuous air injection, illustrating that the early implementing air injection favors restricting water cut in a water-flooded reservoir. A longer water flood period before implementing air injection is detrimental to production performance as well as increasing the cost of lifting, separating, treating, and disposing the great amount of produced water. Hence, air injection should be applied early in the life of field development.

\section{Conclusions}

(1) Air injection in light oil reservoirs is more like a conventional immiscible gas flooding in the initial stage. Thermal effects dominates recovery mechanism when the thermal front approaches the production well after a total of 0.75 pore volume air is injected. The fluctuations of oil rate after thermal breakthrough is the indication of thermal effect. The "pore plugging" effect is revealed through the sudden gas relative permeability decrease caused by the rapid mobilization of oil into the downstream pores.

(2) The oil recovery factor is increased with the increase of $\mathrm{O}_{2}$ content in air, while the incremental oil recovery factor decreases when the $\mathrm{O}_{2}$ content increases from 30 to 50 mol\%. Production performance is not as good as $\mathrm{N}_{2}$ flooding for high $\mathrm{O}_{2}$ content air injection in the initial stage due to the lack of oil swelling brought out by the oleic phase soluble $\mathrm{N}_{2}$. Combining with low $\mathrm{O}_{2}$ and rich $\mathrm{O}_{2}$ content air injection strategy can result in both favorable thermal effects and $\mathrm{O}_{2}$ breakthrough delay.

(3) $E_{a k}$ only controls reaction rate and is not directly responsible for production performance. If low $E_{a k}$ favors to generate more $\mathrm{C}_{2} \mathrm{C}_{5}$ and $\mathrm{CO}_{2}$ that should be benefit for oil recovery, while in favor of producing more $\mathrm{H}_{2} \mathrm{O}$, insoluble $\mathrm{CO}$ and $\mathrm{CH}_{4}$ at low $E_{a k}$ is detrimental or at least does not show positive effects for oil recovery.

(4) The oil recovery factor is not sensitive to intake air temperature. Injecting air from updip provides better production performance than air injection from downdip. However, air injection from downdip can achieve a higher oil recovery factor in an 
early period due to gas override. The development scheme of primary depletion followed by air injection is desirable to perform maximum oil recovery factor as well as low water cut.

\section{Nomenclature}

Selected list of acronyms and units

\begin{tabular}{|c|c|}
\hline EOR & enhanced oil recovery \\
\hline LTO & low temperature oxidation \\
\hline $\mathrm{CO}$ & carbon monoxide \\
\hline $\mathrm{CO}_{2}$ & carbon dioxide \\
\hline $\mathrm{O}_{2}$ & oxygen \\
\hline $\mathrm{N}_{2}$ & nitrogen \\
\hline $\mathrm{H}_{2} \mathrm{O}$ & water \\
\hline $\mathrm{CH}_{4}$ & methane \\
\hline MSCF & 103 standard cubic feet \\
\hline STB & stock tank barrels \\
\hline GOR & gas oil ratio \\
\hline${ }^{\mathrm{o}} \mathrm{API}$ & $\left.31.5+{ }^{\circ} \mathrm{API}\right) \quad=\mathrm{g} / \mathrm{cm}^{3}$ \\
\hline bbl $\times 1.5$ & $\mathrm{E}-01=\mathrm{m}^{3}$ \\
\hline $1 \mathrm{bm} \times 4$ & $\mathrm{E}-01=\mathrm{kg}$ \\
\hline Btu $\times 1$ & $\mathrm{E}+00=\mathrm{kJ}$ \\
\hline${ }^{\circ} \mathrm{F} \quad\left({ }^{\circ} \mathrm{F}\right.$ & $={ }^{\circ} \mathrm{C}$ \\
\hline psi $\times 6.8$ & $\mathrm{E}+00=\mathrm{kPa}$ \\
\hline $\mathrm{ft} \times 3.04$ & $\mathrm{E}-01=\mathrm{m}$ \\
\hline $\mathrm{cp} \times 1.0$ & $\mathrm{E}-03=\mathrm{Pa} . \mathrm{s}$ \\
\hline $\mathrm{mD} \times 9$ & $\mathrm{E}-04=\mu \mathrm{m}^{2}$ \\
\hline
\end{tabular}

\section{Acknowledgments}

This work is supported by a fund from the National Science Foundation of China (Award No. 51404202) and the U.S. Department of Energy (Award No. DE-FE0024311). We would like to thank the Computer Modeling Group Limited (CMGL), Calgary, Canada for providing their reservoir simulators to Texas Tech University. The authors would like to express their sincere 
appreciation to fuel editors and technique reviewers for their constructive comments to improve this paper.

\section{Reference}

[1] Watts, B. C., Hall, T. F. and Petri, D. J. 1997. Horse Creek Air-Injection Project: An Overview. Presented at the SPE rocky mountain regional meeting, Casper, Wyoming, 18-21 May. SPE-38359-MS. http://dx.doi.org/10.2118/38359-MS.

[2] Clara, C., Zelenka, V., Schirmer, P. et al. 1998. Appraisal of the HORSE CREEK Air Injection Project Performance. Presented at the Abu Dhabi International Petroleum Exhibition and Conference, Abu Dhabi, U.A.E., 11-14 October. SPE-49519-MS. http://dx.doi.org/10.2118/49519-MS.

[3] Gillham, T. H., Cerveny, B. W., Fornea, M. A. et al. 1998. Low cost IOR an update on the W. Hackberry air injection project. Presented at the SPE/DOE Improved Oil Recovery Symposium, Tulsa, Oklahoma, 19-22 April. SPE-39642-MS. http://dx.doi.org/10.2118/39642-MS.

[4] Glandt, C. A., Pieterson, R., Dombrowski, A. et al. 1999. Coral creek field study a comprehensive assessment of the potential of high-pressure air injection in a mature waterflood project. Presented at the SPE Mid-Continent Operations Symposium, Oklahoma City, Oklahoma, 28-31 March. SPE-52198-MS. http://dx.doi.org/10.2118/52198-MS.

[5] Gutierrez, D., Miller, R. J., Taylor, A. R. et al. 2009. Buffalo field high-pressure air injection projects 1977 to 2007 technical performance and operational challenges. SPE Reservoir Evaluation \& Engineering, 12(04), 542-549. SPE-113254-PA. http://dx.doi.org/10.2118/113254-PA.

[6] Fassihi, M. R., Yannimaras, D. V. and Kumar, V. K. 1997. Estimation of recovery factor in light-oil air-injection projects, SPE Reservoir Engineering, 12 (3), 173-178. SPE-28733-PA. http://dx.doi.org/10.2118/28733-PA.

[7] Germain, P. and Geyelin, J. L. 1997. Air Injection into a Light Oil Reservoirs: The Horse Creek Project. Presented at the Middle East Oil, Bahrain, 15-18 March. SPE-37782-MS. http://dx.doi.org/10.2118/37782-MS.

[8] Greaves, M., Ren, S. R. and Rathbone, R. R. 1998. Air injection for IOR from light-oil reservoirs: oxidation rate and displacement studies. Presented at the SPE/DOE Improved Oil Recovery Symposium, Tulsa, Oklahoma, 19-22 April. SPE-40062-MS. http://dx.doi.org/10.2118/40062-MS.

[9] Gutierrez, D., Taylor, A. R., Kumar, V. et al. 2008. Recovery factors in high-pressure air injection projects revisited. SPE Reservoir Evaluation \& Engineering, 11 (06), 1097-1106. SPE-108429-PA. http://dx.doi.org/10.2118/108429-PA.

[10]_Ruidas, B.C. and Ganguly, S. 2015. In Situ Combustion of Light Oil: Stoichiometric, Kinetic, and Thermodynamic Analyses from the Flow Experiments. Combustion Science and Technology, 187, 10, 1542-1561. http://dx.doi.org/10.1080/00102202.2015.1050553

[11]_Ahmadi, M. A., Masoumi, M., and Askarinezhad, R. 2015. Evolving Smart Model to Predict the Combustion Front Velocity for In Situ Combustion. Energy Technology, 3(2), 128-135. http://dx.doi.org/10.1002/ente.201402104

[12]_Muraza, O. and Galadima, A. 2015. Aquathermolysis of heavy oil: A review and perspective on catalyst development. Fuel, 157, 219-231. http://dx.doi.org/10.1016/i.fuel.2015.04.065

[13] Khansari, Z., Kapadia, P., Mahinpey, N. et al. 2014. A new reaction model for low temperature 
oxidation of heavy oil: Experiments and numerical modeling. Energy, 64, 419-428. http://dx.doi.org/10.1016/j.energy.2013.11.024

[14] Khansari, Z., Gates, I. D., and Mahinpey, N. 2014. Low-temperature oxidation of Lloydminster heavy oil: Kinetic study and product sequence estimation. Fuel, 115, 534-538. http://dx.doi.org/10.1016/i.fuel.2013.07.071

[15] Turta, A. T. and Singhal, A. K. 2001. Reservoir engineering aspects of light-oil recovery by air injection, SPE Reservoir Evaluation \& Engineering, 4 (04), 336-344. http://dx.doi.org/10.2118/72503-PA

[16] Moore, R. G., Mehta, S. A. and Ursenbach, M. G. 2002. A Guide to High Pressure Air Injection (HPAI) Based Oil Recovery. Presented at the SPE/DOE Improved Oil Recovery Symposium, Tulsa, OK, 13-17 April. SPE-75207-MS. http://dx.doi.org/10.2523/75207-MS.

[17] Dutton, S. P., Kim, E. M., Broadhead, R. F. et al. 2004. Play analysis and digital portfolio of major oil reservoirs in the Permian Basin Application and Transfer of Advanced Geological and Engineering Technologies for Incremental Production Opportunities. Technical Report DE-FC26-02NT15131, National Energy Technology Laboratory (NETL) for the United States Department of Energy.

[18] Hughes, B. L and Sarma, H. K. 2006. Burning Reserves for Greater Recovery? Air Injection Potential in Australian Light Oil Reservoirs. Presented at the Asia Pacific Oil \& Gas Conference and Exhibition, Adelaide, Australia, 11-13 Sept.SPE-101099-MS. http://dx.doi.org/10.2118/101099-MS.

[19] Jia, H., Yuan, C. D., Zhang, Y. et al. 2012 a. Recent progress of high pressure air injection process (HPAI) in light oil reservoir: laboratory investigation and field application. Presented at the SPE Heavy Oil Conference Canada, Calgary, Alberta, 12-14 June. SPE-156974-MS. http://dx.doi.org/10.2118/156974-MS.

[20] Jia, H. 2012 b. Investigation into the oxidation mechanism of crude oil and gas channeling prevention for application of high-pressure air injection (HPAl) process, PhD dissertation, Southwest Petroleum University. http://thebestthesis.com/?doc/1699925

[21] Jia, H, Zhao, J. Z., Pu, W. F. et al. 2012 c. Laboratory investigation on the feasibility of light-oil autoignition for application of the high-pressure air injection (HPAI) process. Energy Fuels, 26 (9), 5638-5645. http://dx.doi.org/10.1021/ef301012d.

[22] Fassihi, M. R., Moore, R. G., Mehta, S. A. and Ursenbach, M. G. 2015. Safety Considerations for High-Pressure Air Injection Into Light-Oil Reservoirs and Performance of the Holt Sand Unit Project. SPE Production \& Operations, 30 (4), 1-10. SPE-169168-PA. http://dx.doi.org/10.2118/169168-PA

[23] Sakthikumar, S., Madaoui, K. and Chastang, J. 1995. An investigation of the feasibility of air injection into a waterflooded light oil reservoir. Presented at the SPE Middle East Oil Show, Bahrain, 11-14 March. SPE- 29806-MS. http://dx.doi.org/10.2118/29806-MS

[24] Greaves M., Ren S. R., Rathbone R. R., et al., 2000. Improved Residual Light Oil Recovery by Air Injection (LTO Process). Journal of Canadian Petroleum Technology, 2000, 39 (01), 57-61. http://dx.doi.org/10.2118/00-01-05

[25] Yu, M., Ren S. R., Niu B., et al. 2010. Experimental on Oxidation Reaction Rate for EOR by Air Injection in Light-Oil Reservoirs, Journal of Petrochemical Universities, 23(03), 55-57. http://dx.chinadoi.cn/10.3969\%2fj.issn.1006-396X.2010.03.013

[26] Jia, H., Zhao, J. Z., and Pu, W. F. 2012 c. Numerical Analysis on the Influence of Thermal Effects on 
Oil Flow Characteristic in High-Pressure Air Injection (HPAI) Process, Journal of Applied Mathematics, 2012, 1-17. http://dx.doi.org/10.1155/2012/736125.

[27] Ursenbach M. G., Moore R. G., Mehta S. A., 2010. Is High-Pressure Air Injection (HPAI) Simply a Flue-Gas Flood? Journal of Canadian Petroleum Technology, 49(02), 56-63. SPE-133206-PA. http://dx.doi.org/10.2118/133206-PA.

[28] Gutiérrez D., Moore R. G., Mehta, S. A. et al. 2009. The Challenge of Predicting Field Performance of Air Injection Projects Based on Laboratory and Numerical Modelling. Journal of Canadian Petroleum Technology, 48(04), 23-34. PETSOC-09-04-23-DA. http://dx.doi.org/10.2118/09-04-23-DA

[29]Ursenbach, M. G., Moore, R. G. and Mehta, S. A. 2010. Air injection in heavy oil reservoirs-a process whose time has come (again). Journal of Canadian Petroleum Technology, 49(01), 48-54. SPE-132487-PA. http://dx.doi.org/10.2118/132487-PA

[30] Tingas, J., Greaves, M. and Young, T. J. 1996. Field scale simulation study of in-situ combustion in high pressure light oil reservoirs. Presented at the SPE/DOE Improved Oil Recovery Symposium, Tulsa, Oklahoma, 21-24 April. SPE-35395-MS. http://dx.doi.org/10.2118/35395-MS.

[31] Tingas, J. 2000. Numerical simulation of air injection processes in high pressure light $\&$ medium oil reservoirs (Doctoral dissertation, UNIVERSITY OF BATH (UNITED KINGDOM)).

[32] Stegent, N., Wagner, A., Mullen, J. et al. 2010. Engineering a Successful Fracture-Stimulation Treatment in the Eagle Ford Shale. Presented at the Tight Gas Completions Conference, San Antonio, Texas, 2-3 November. SPE-136183-MS. http://dx.doi.org/10.2118/136183-MS.

[33] Bruner, K. R. and Smosna, R. 2011. A comparative study of the Mississippian Barnett Shale, Fort Worth Basin, and Devonian Marcellus Shale. Appalachian Basin Technical Report DOE/NETL-2011/1478, National Energy Technology Laboratory (NETL) for The United States Department of Energy.

[34] Cox, S. A., Cook, D., Dunek, K. et al. 2008. Unconventional resource play evaluation: A look at the Bakken Shale Play of North Dakota. Presented at the SPE Unconventional Reservoirs Conference, Keystone, Colorado, 10-12 February. SPE-114171-MS. http://dx.doi.org/10.2118/114171-MS.

[35]_Chu, Y., Fan, C., Zhang, Q. et al. 2014. The oxidation of heavy oil to enhance oil recovery: The numerical model and the criteria to describe the low and high temperature oxidation. Chemical Engineering Journal, 248, 422-429. http://dx.doi.org/10.1016/..cej.2014.03.036

[36] CMG. STARS User's Guide, Computer Modeling Group Ltd, 2014.

[37] CMG. WinProp User's Guide, Computer Modeling Group Ltd, 2014.

[38] Zelenko, V. and Solignac, F. 1997. Use of accelerating rate calorimeter in reservoir oil selection for air injection process. Presented at the 7th Petroleum Conference, South Saskatchewan Section, Petroleum Society of CIM, Regina. pp. 19-22.

[39] Ambastha A. K. and Kumar M. 1999. New Insights into In-Situ Combustion Simulation for Heavy Oil Reservoirs. Presented at the SPE Annual Technical Conference and Exhibition, Houston, Texas, 3-6 October. SPE-56543-MS. http://dx.doi.org/10.2118/56543-MS.

[40] Ren, S. R., Greaves, M. and Rathbone, R. R. 2002. Air injection LTO process: An IOR technique for light-oil reservoirs. SPE Journal, 7 (01), 90-99. SPE-57005-PA. http://dx.doi.org/10.2118/57005-PA.

[41] Dembla Dhiraj, B. E. 2004. Simulating enhanced oil recovery (EOR) by high-pressure air injection (HPAl) in West Texas light oil reservoir, Msc. thesis, The University of Texas at Austin.

[42] de Zwart A. H., Van Batenburg D. W., Blom C. P. A., et al., 2008. The Modeling Challenge of 
High-Pressure Air Injection. Presented at the SPE Symposium on Improved Oil Recovery, Tulsa, Oklahoma, USA, 20-23 April, SPE-113917-MS. http://dx.doi.org/10.2118/113917-MS.

[43] Jia, H., Zhao, J. Z., Yang, H. J. et al. 2014. Numerical simulation of mechanism of high-pressure air injection (HPAI) in light oil reservoirs. Petroleum Exploration and Development, 41 (02), 235-243. http://dx.doi.org/10.1016/s1876-3804

[44] Barzin, Y., Moore, R. G., Mehta, S. A., et al. 2013. A comprehensive kinetics model for light oil oxidation/combustion reactions under high pressure air injection process (HPAI). Presented at the SPE Annual Technical Conference and Exhibition held in New Orleans, Louisiana, USA, 30 September-2 October. SPE-166483-MS. http://dx.doi.org/10.2118/166483-MS

[45] Gates, C. F. and Ramey Jr., H. J. 1980. A Method for Engineering In-Situ Combustion Oil Recovery Projects. J Pet Technol, 32 (2), 385-294. SPE-7149-PA. http://dx.doi.org/10.2118/7149-PA. 


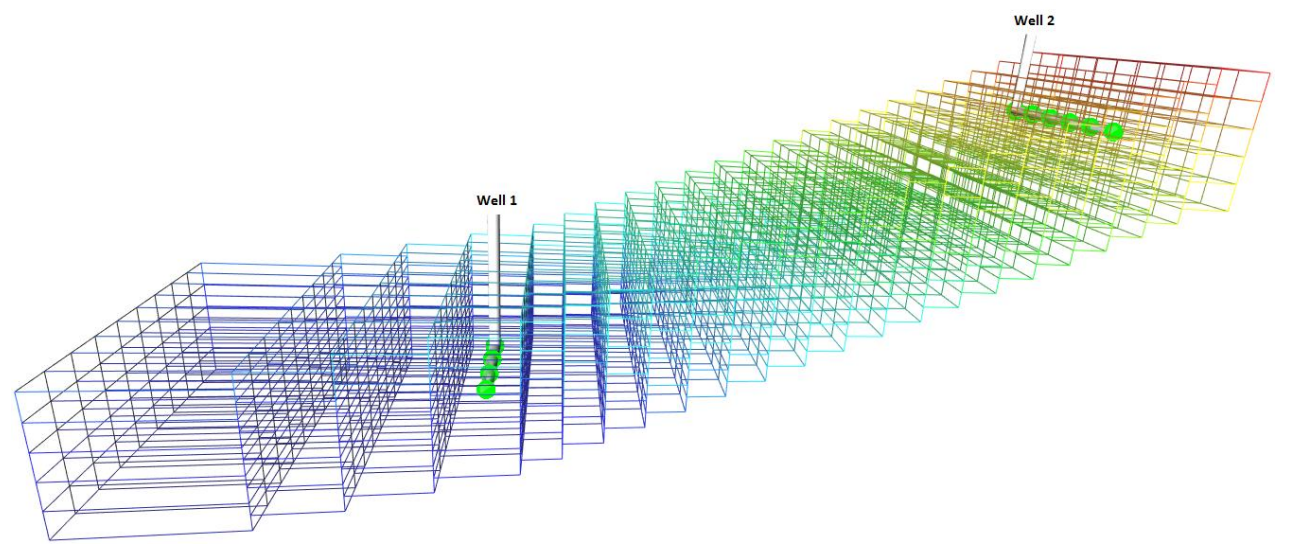

Figure 1. 3-D reservoir simulation model 
Table 1. Compositional data for the Peng-Robinson EOS in the simulation

\begin{tabular}{l|lcccl}
\hline Component & $\begin{array}{c}\text { Molar } \\
\text { fraction }\end{array}$ & $\begin{array}{c}\text { Critical } \\
\text { pressure } \\
(\mathrm{psi})\end{array}$ & $\begin{array}{c}\text { Critical } \\
\text { temperature } \\
\left({ }^{\circ} \mathrm{F}\right)\end{array}$ & $\begin{array}{c}\text { Molar } \\
\text { weight } \\
(\mathrm{g} / \mathrm{gmol})\end{array}$ & \multicolumn{1}{c}{ Solubility } \\
\hline $\mathrm{C}_{21+}$ & 0.1399 & 252.44 & 832.17 & 539.37 & Oleic phase soluble \\
$\mathrm{C}_{11} \mathrm{C}_{20}$ & 0.3387 & 273.68 & 809.35 & 209.72 & Oleic phase soluble \\
$\mathrm{C}_{6}-\mathrm{C}_{10}$ & 0.0605 & 391.31 & 522.92 & 102.06 & Oleic phase soluble \\
$\mathrm{C}_{2} \mathrm{C}_{5}$ & 0.2319 & 609.93 & 213.82 & 46.93 & Oleic phase soluble \\
$\mathrm{CH}_{4}$ & 0.2290 & 667.17 & -116.59 & 16.04 & Oleic phase soluble \\
$\mathrm{CO}_{2}$ & $/$ & 1069.80 & 87.89 & 44.01 & Oleic phase soluble \\
$\mathrm{N}_{2}$ & $/$ & 492.26 & -232.51 & 28.01 & Oleic phase soluble \\
$\mathrm{O}_{2}$ & $/$ & 731.86 & -181.39 & 31.99 & Oleic phase insoluble \\
$\mathrm{CO}$ & $/$ & 507.05 & -220.45 & 28.01 & Oleic phase insoluble \\
$\mathrm{H}_{2} \mathrm{O}$ & $/$ & 3155.00 & 705.70 & 18.00 & Aqueous phase \\
$\mathrm{Coke}$ & $/$ & & & 13.60 & Solid phase \\
\hline
\end{tabular}




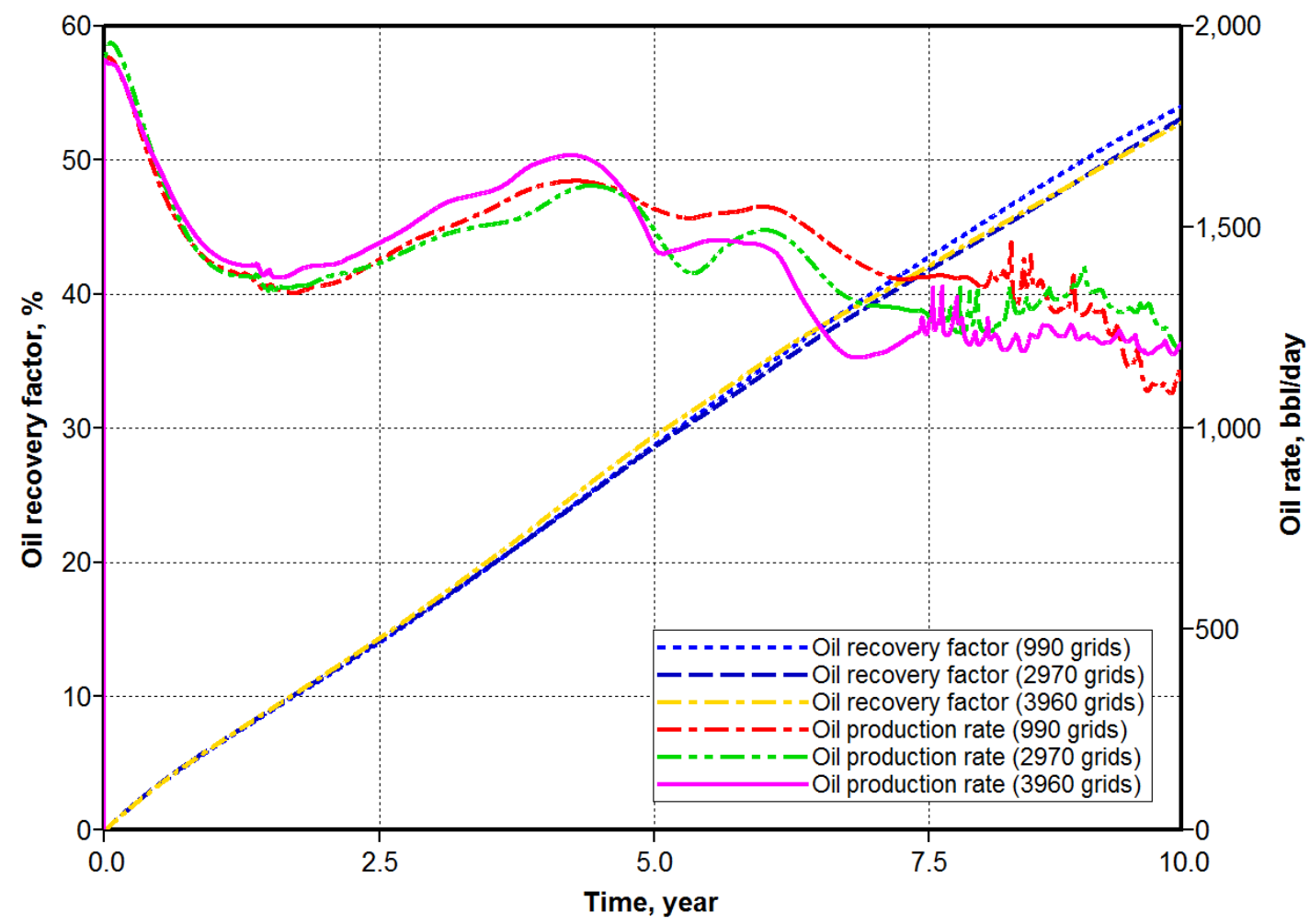

Figure 2. Effect of grid resolution on production performance of air injection 


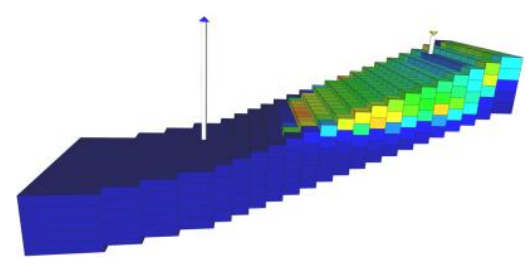

(a)

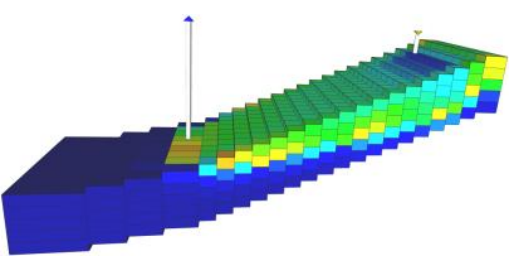

(b)

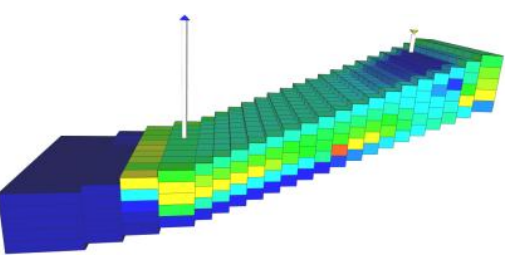

(c)

Figure 3. Reservoir temperature distribution: (a) at 5 years, (b) at 7.5 years, (c) at 10 years.

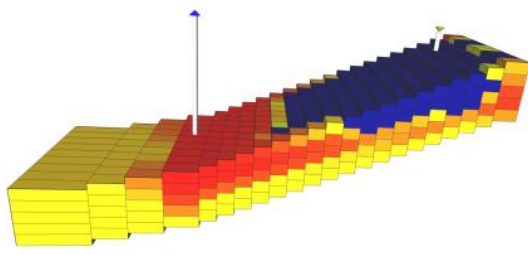

(a)

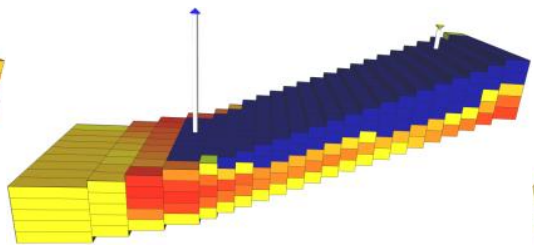

(b)

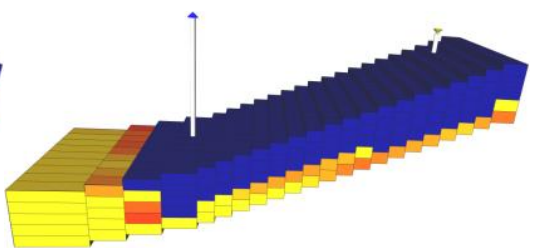

(c)

Figure 4. Crude oil viscosity distribution: (a) at 5 years, (b) at 7.5 years, (c) at 10 years. 


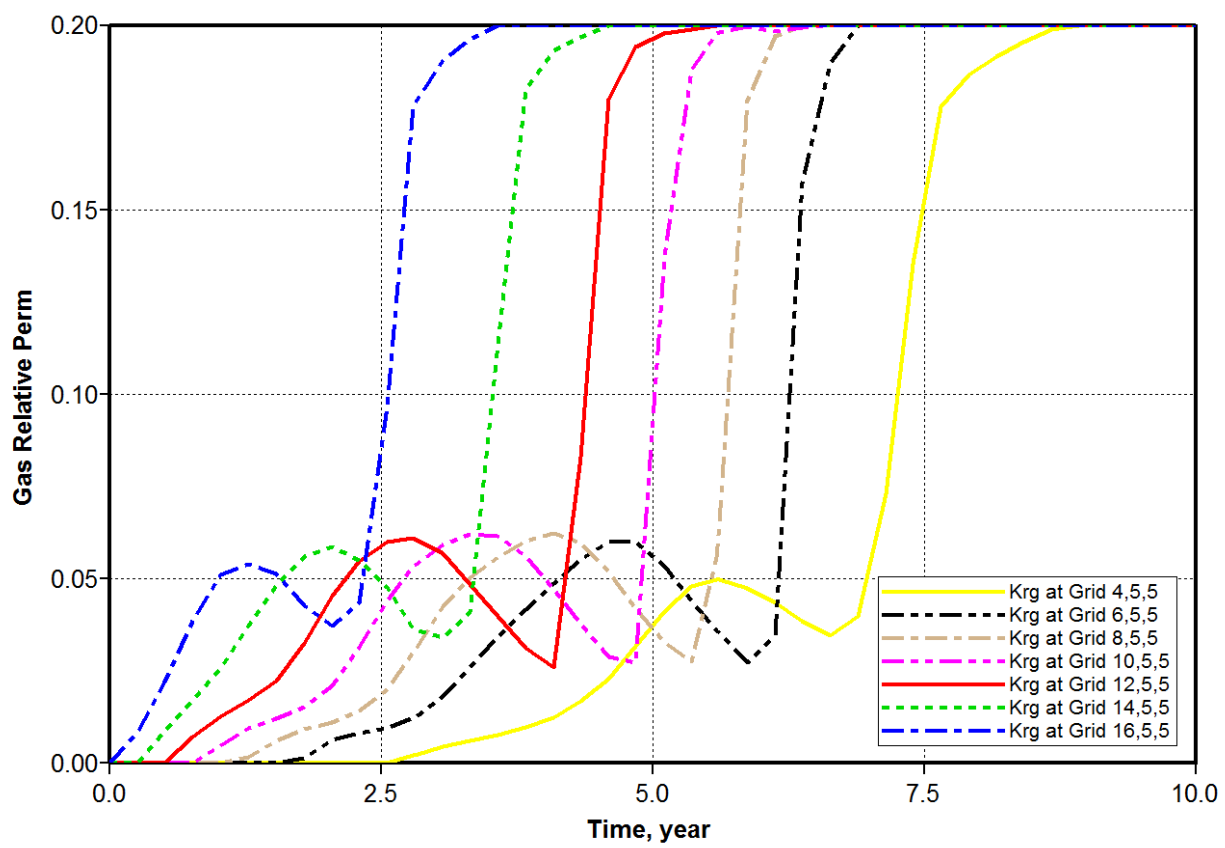

Figure 5. Variation of gas relative permeability for air injection in the base case

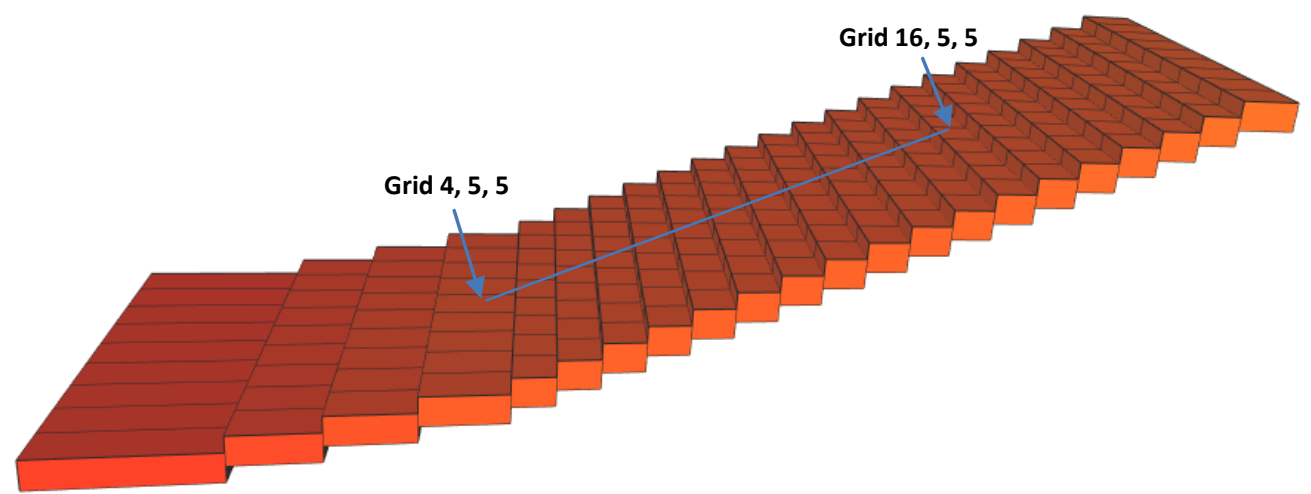

Figure 6. Location of selected grids 


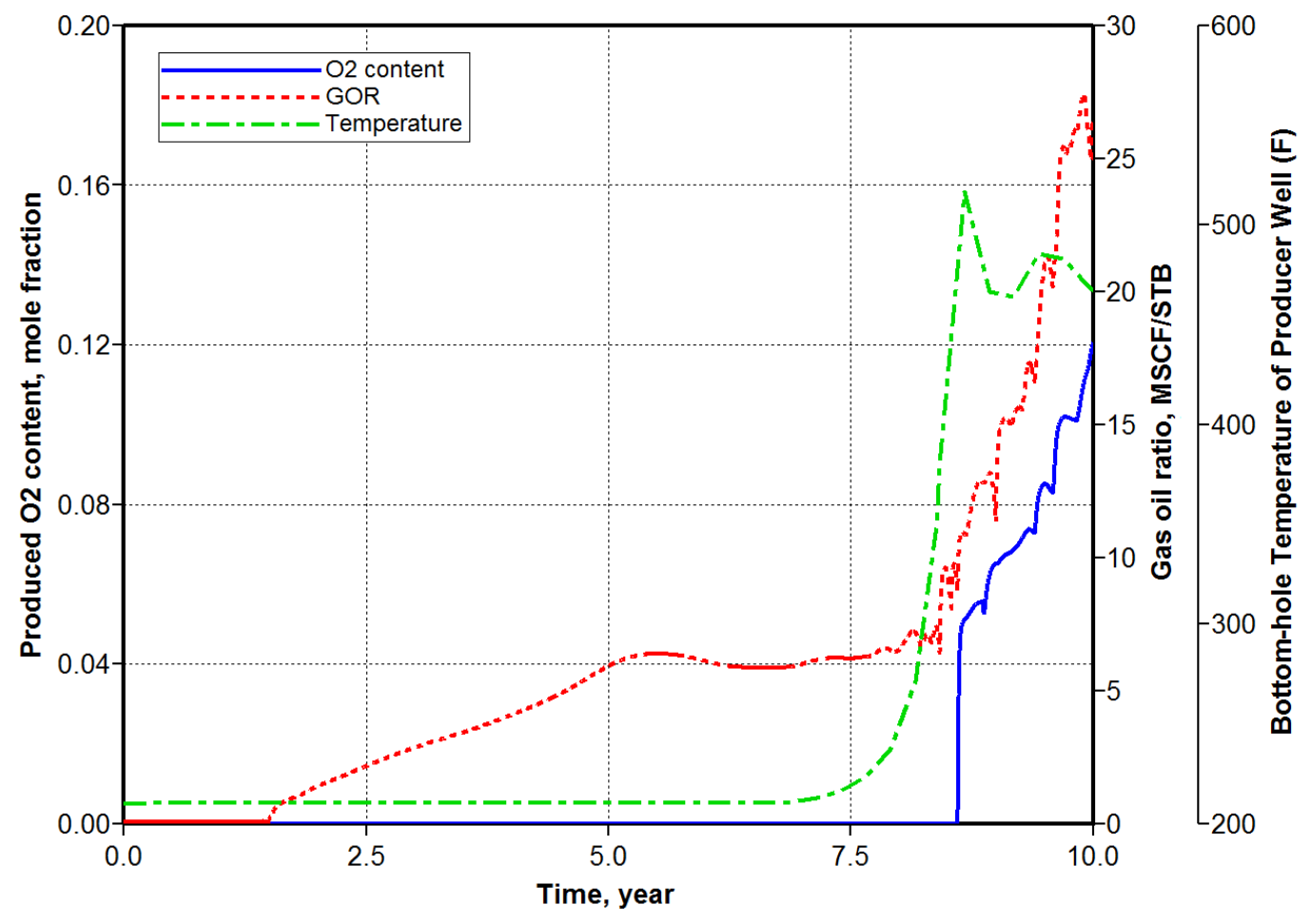

Figure 7. Producer well performance during air injection process 


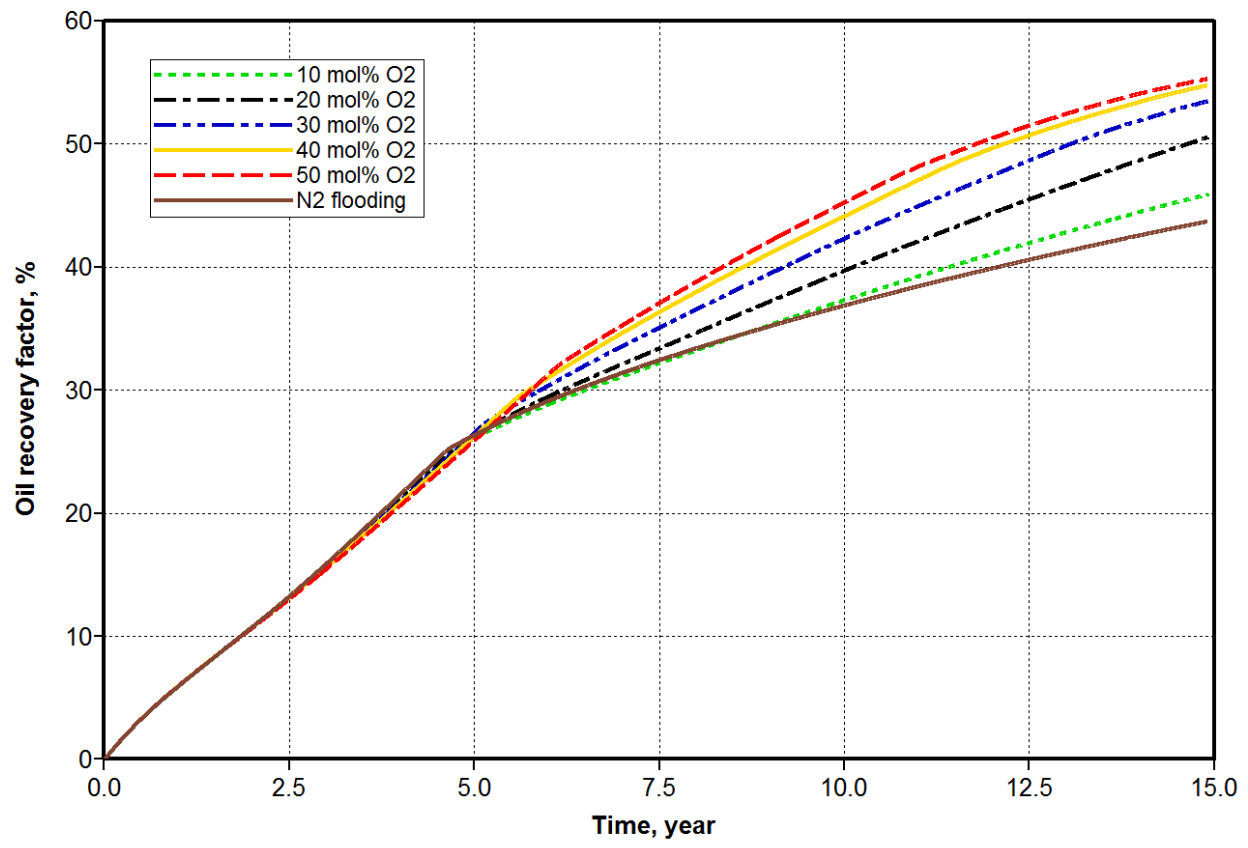

Figure 8. Effect of $\mathrm{O}_{2}$ concentration on oil recovery factor at different injection cases 


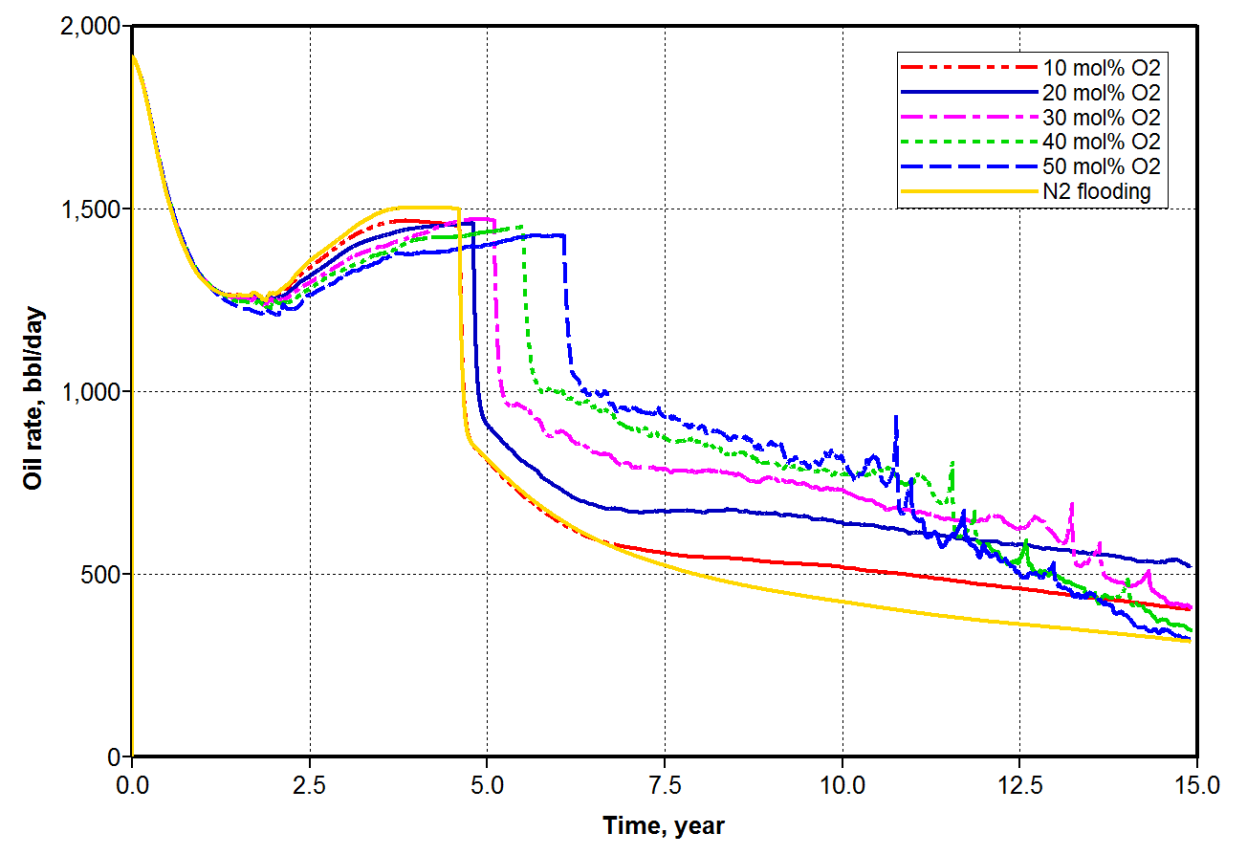

Figure 9. Effect of $\mathrm{O}_{2}$ concentration on oil rate at different injection cases 


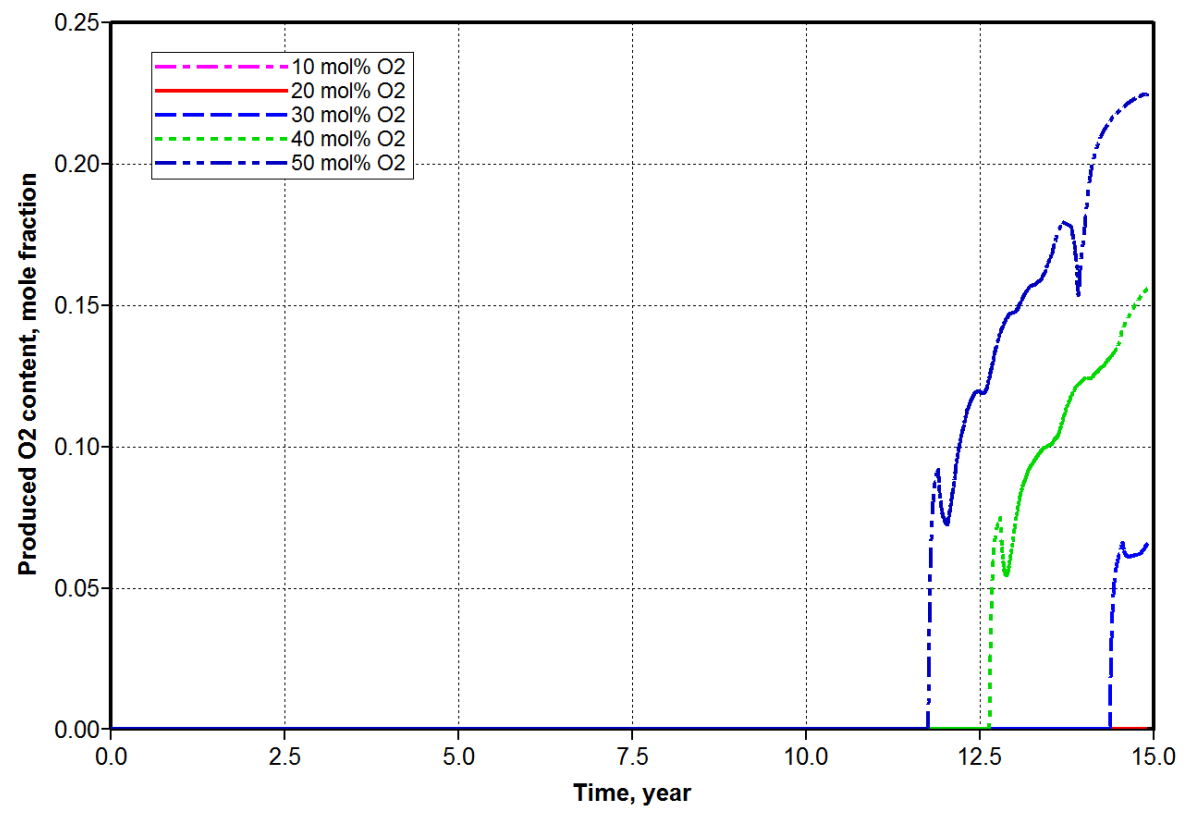

Figure 10. Produced $\mathrm{O}_{2}$ mole fraction at different injection cases 


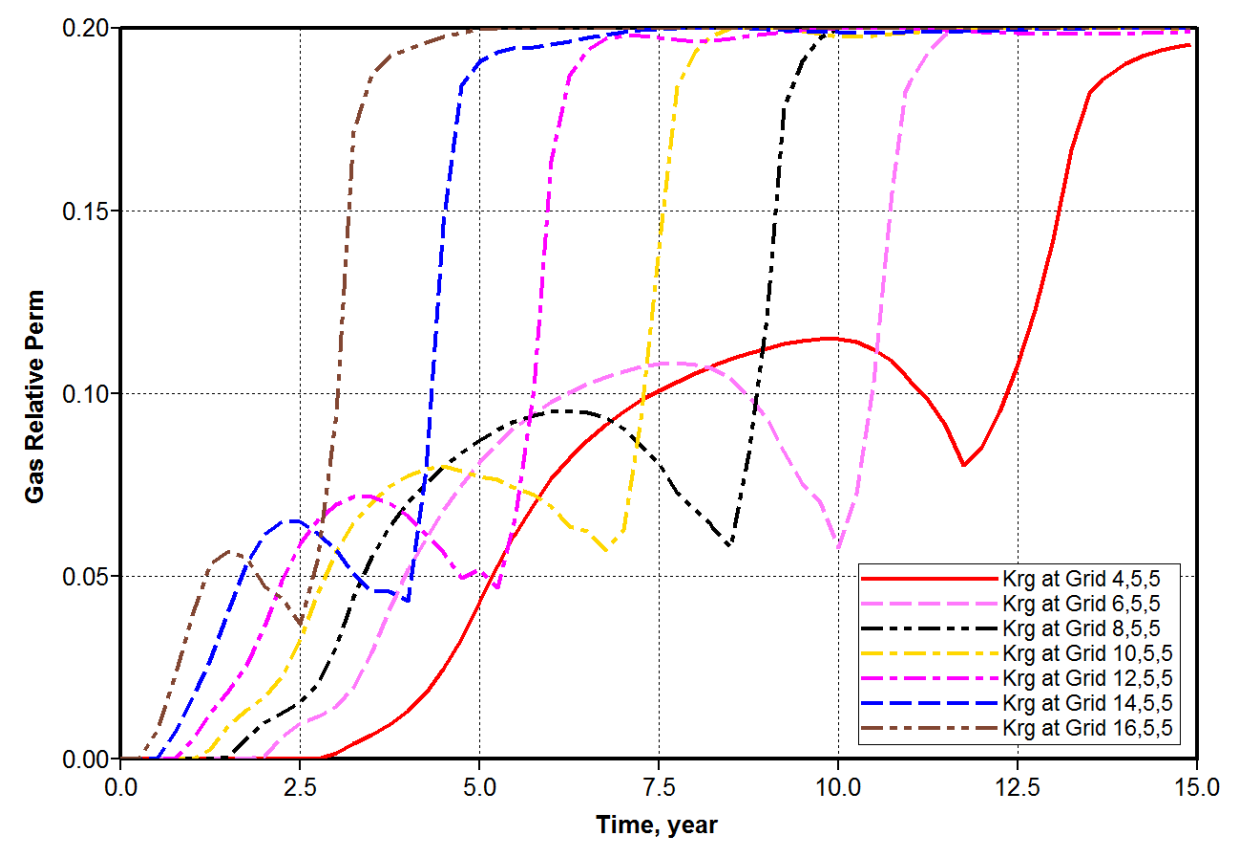

Figure 11. Variation of gas relative permeability for air injection with $20 \mathrm{~mol} \% \mathrm{O}_{2}$

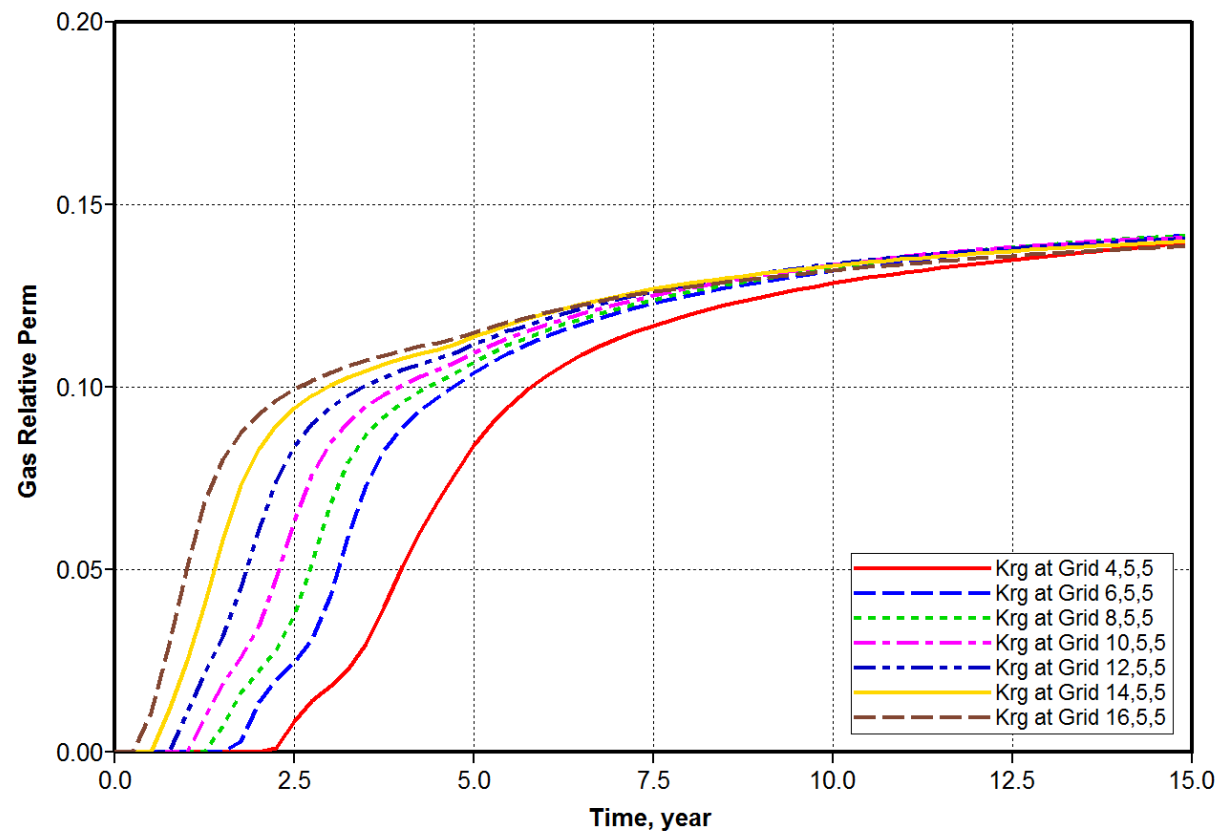

Figure 12. Variation of gas relative permeability for $\mathrm{N}_{2}$ flooding 


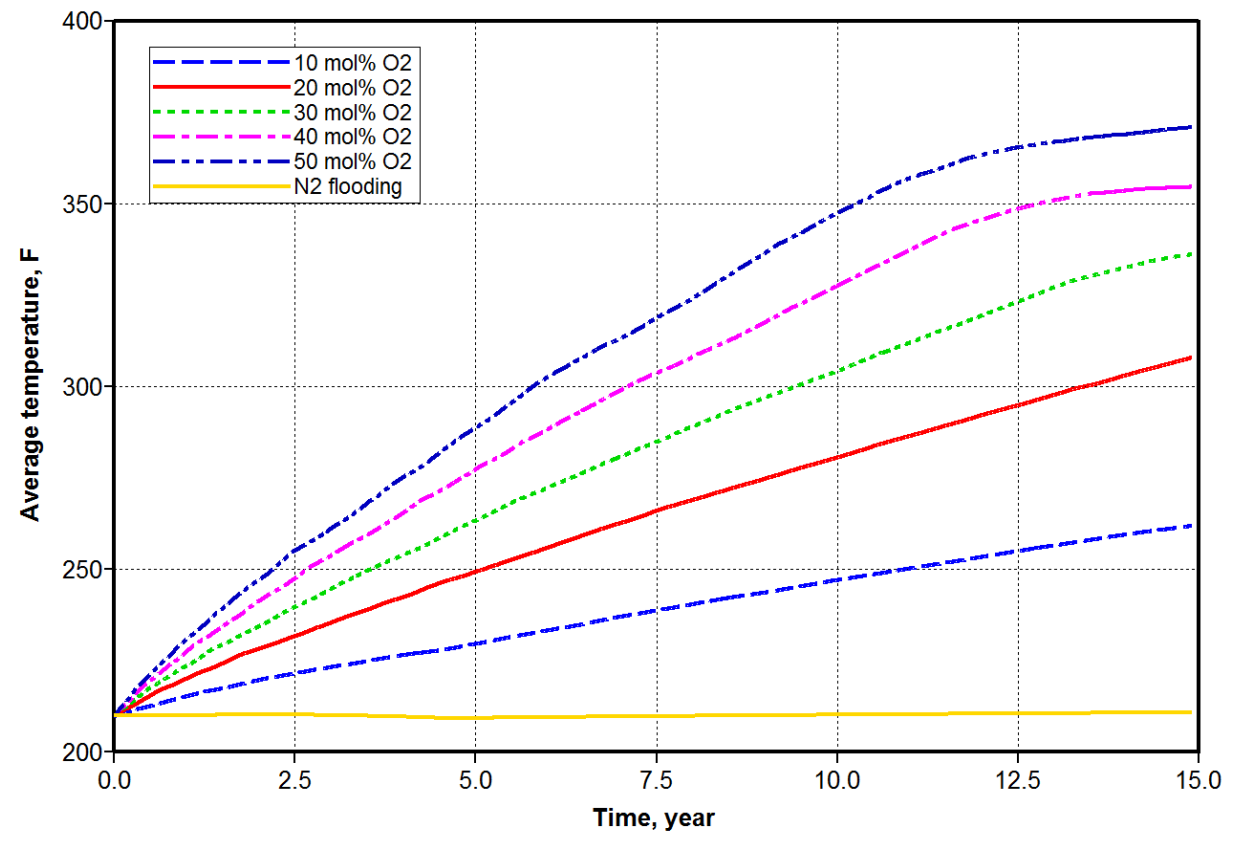

Figure 13. Effect of $\mathrm{O}_{2}$ concentration on average reservoir temperature at different injection cases 
Table 2. Summary of oil recovery factor at different activation energies

\begin{tabular}{|c|c|c|c|c|c|}
\hline Reactions & Description & Frequency Factor & $\begin{array}{c}\text { Enthply, } \\
\text { Btu/lbmole }\end{array}$ & $\begin{array}{c}\text { Activation Energy, } \\
\text { Btu/lbmole }\end{array}$ & $\begin{array}{c}\text { Oil Recovery } \\
\text { Factor, \% }\end{array}$ \\
\hline \multirow[t]{4}{*}{ Reaction 1} & $\mathrm{C}_{21+}$ cracking (with $\mathrm{CH}_{4}$ & $1.274 \mathrm{E}+5$ & 0 & 30000 & 49.70 \\
\hline & Generation) & & & 34000 & 49.76 \\
\hline & & & & 38000 & 50.55 \\
\hline & & & & 42000 & 50.70 \\
\hline \multirow[t]{4}{*}{ Reaction 2} & $\mathrm{C}_{21+}$ cracking (without $\mathrm{CH}_{4}$ & $0.891 \mathrm{E}+5$ & 0 & 31000 & 53.00 \\
\hline & Generation) & & & 35000 & 50.75 \\
\hline & & & & 39000 & 50.55 \\
\hline & & & & 43000 & 50.53 \\
\hline \multirow[t]{3}{*}{ Reaction 3} & $\mathrm{C}_{11-20}$ cracking & $0.500 \mathrm{E}+5$ & 0 & 40000 & 50.54 \\
\hline & & & & 45000 & 50.55 \\
\hline & & & & 50000 & 50.55 \\
\hline \multirow[t]{3}{*}{ Reaction 4} & $\mathrm{C}_{21+}$ combustion & $3.846 \mathrm{E}+10$ & 10294 & 2000 & 44.77 \\
\hline & & & & 6000 & 46.65 \\
\hline & & & & 10000 & 49.42 \\
\hline \multirow[t]{3}{*}{ Reaction 5} & $\mathrm{C}_{11-20}$ combustion & $3.846 \mathrm{E}+10$ & 4920 & 2000 & 48.65 \\
\hline & & & & 6000 & 49.89 \\
\hline & & & & 10000 & 50.71 \\
\hline \multirow[t]{3}{*}{ Reaction 6} & $\mathrm{C}_{6-10}$ combustion & $3.846 \mathrm{E}+10$ & 2420 & 2000 & 49.86 \\
\hline & & & & 6000 & 49.98 \\
\hline & & & & 10000 & 50.26 \\
\hline \multirow[t]{3}{*}{ Reaction 7} & $\mathrm{C}_{2-5}$ combustion & $3.846 \mathrm{E}+10$ & 1463 & 2000 & 47.69 \\
\hline & & & & 6000 & 49.13 \\
\hline & & & & 10000 & 50.28 \\
\hline \multirow[t]{3}{*}{ Reaction 8} & Coke combustion & $0.300 \mathrm{E}+6$ & 461 & 2000 & 50.55 \\
\hline & & & & 6000 & 50.55 \\
\hline & & & & 10000 & 50.55 \\
\hline \multirow[t]{3}{*}{ Reaction 9} & $\mathrm{CH}_{4}$ combustion & $3.846 \mathrm{E}+10$ & 1463 & 2000 & 50.50 \\
\hline & & & & 6000 & 50.54 \\
\hline & & & & 10000 & 50.55 \\
\hline \multirow[t]{3}{*}{ Reaction 10} & CO combustion & $0.191 \mathrm{E}+5$ & 283800 & 2000 & 50.91 \\
\hline & & & & 6000 & 48.74 \\
\hline & & & & 10000 & 44.85 \\
\hline
\end{tabular}




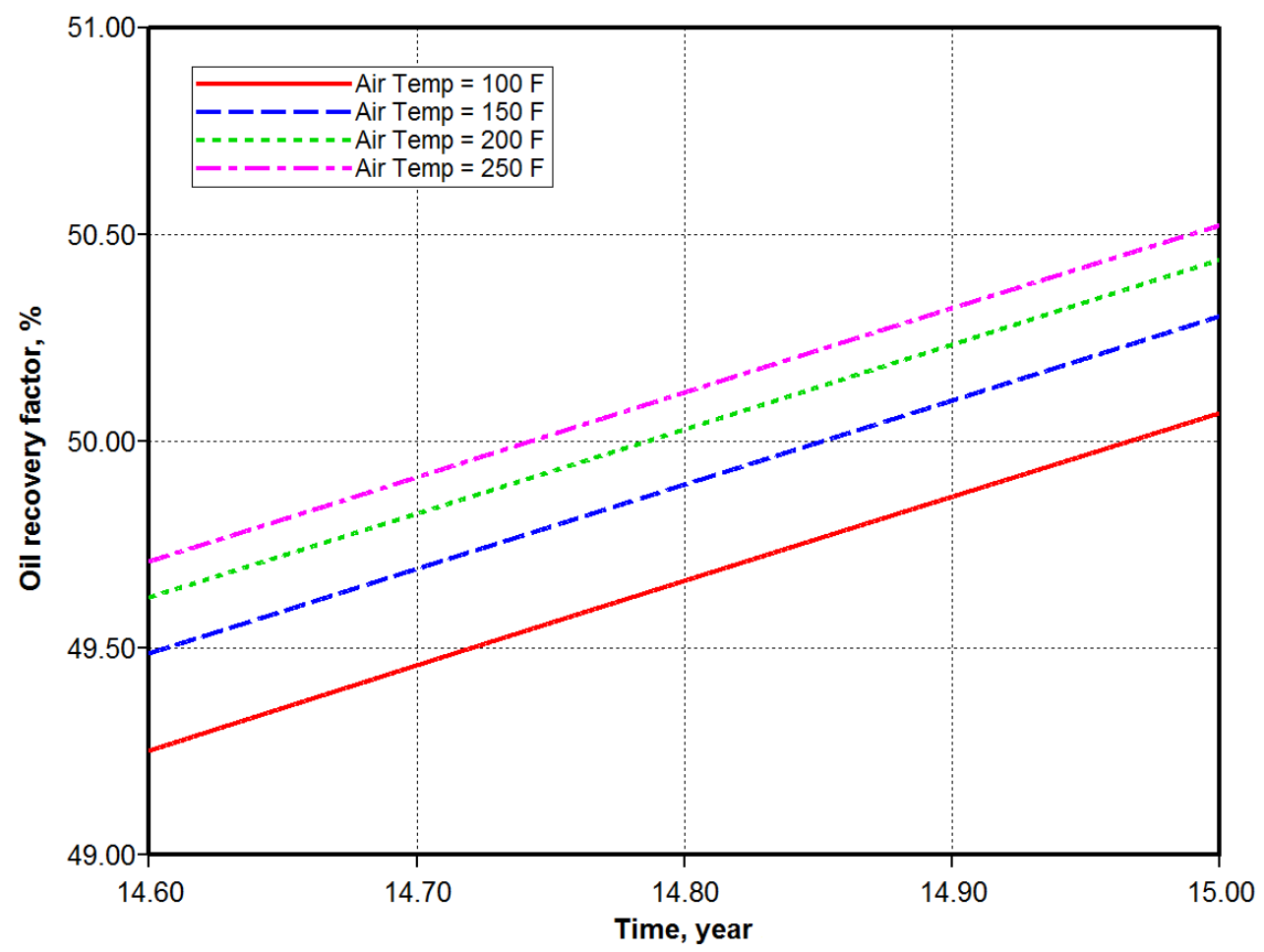

Figure 14. Effect of intake air temperature on oil recovery factor at different injection cases 


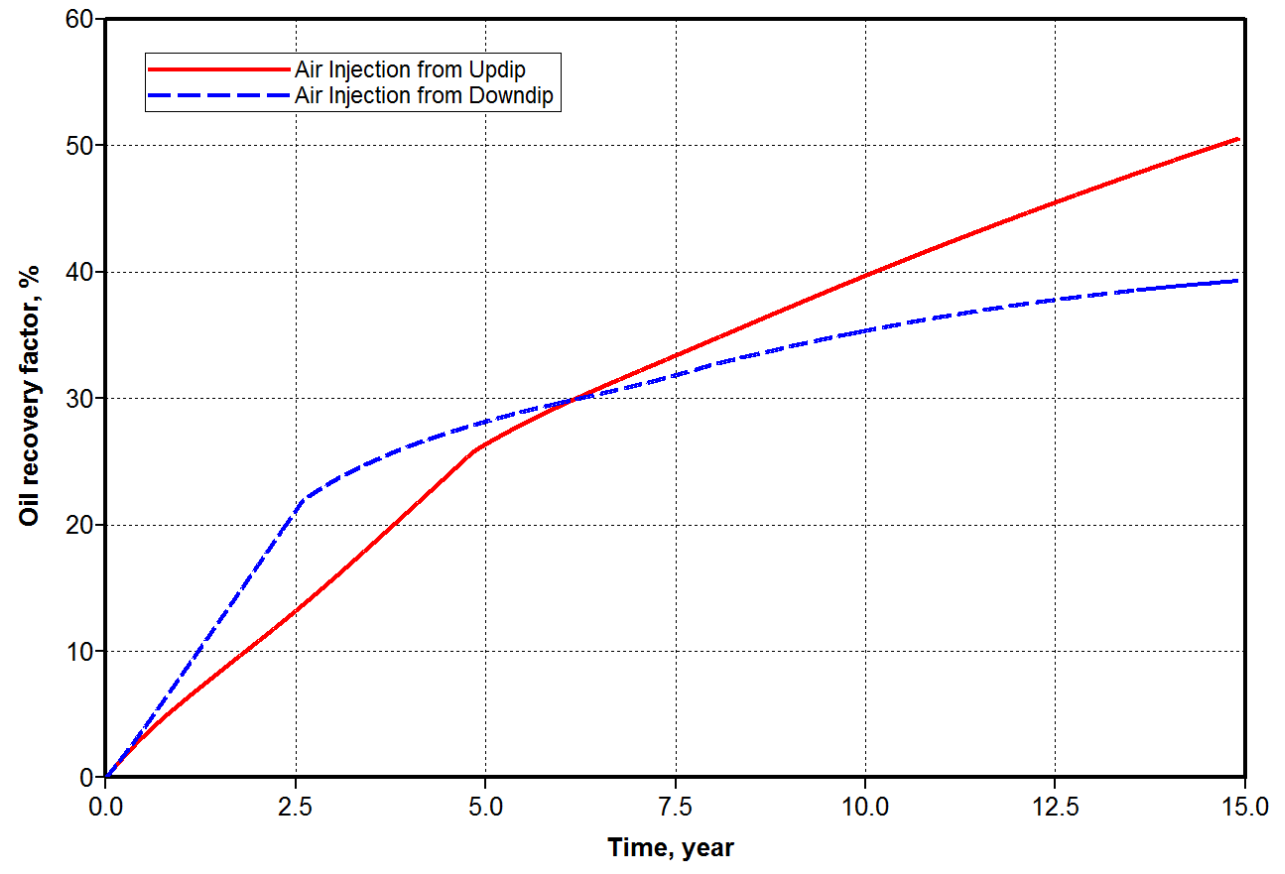

Figure 15. Effect of geological structure of gas injector on oil recovery factor 


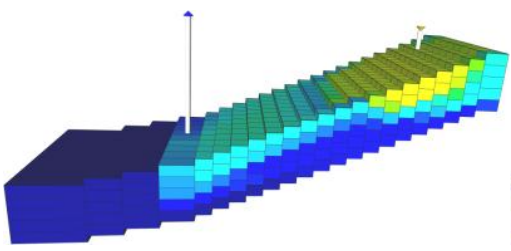

(a)

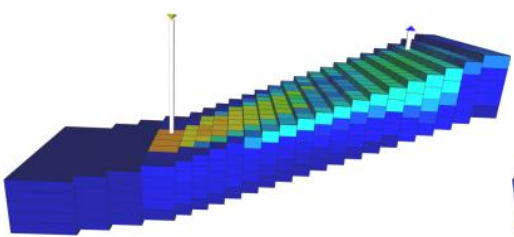

(a)

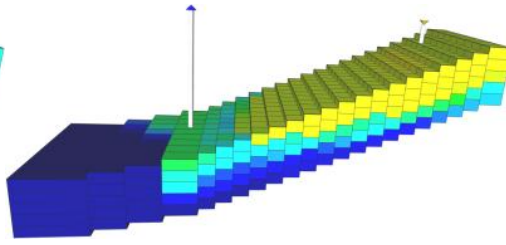

(b)

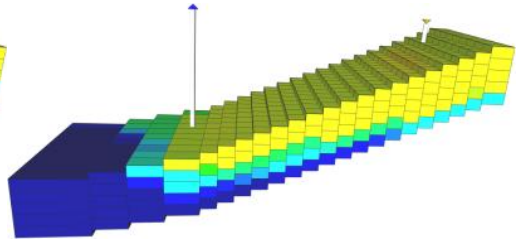

(c)

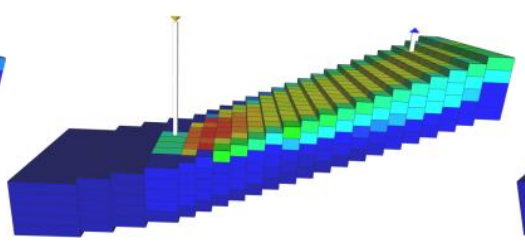

(b)

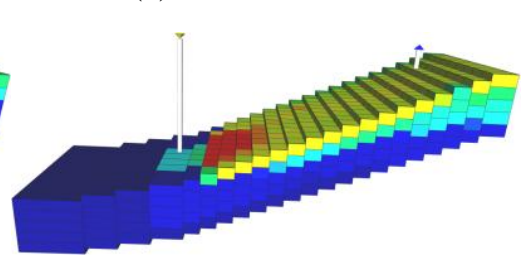

(c)

Figure 16. Gas saturation distributions of air injection from updip (top) and downdip (bottom): (a) at 5 years, (b) at 10 years, (c) at 15 years.

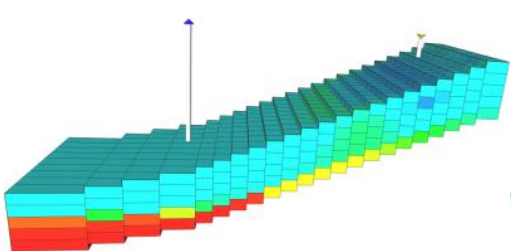

(a)

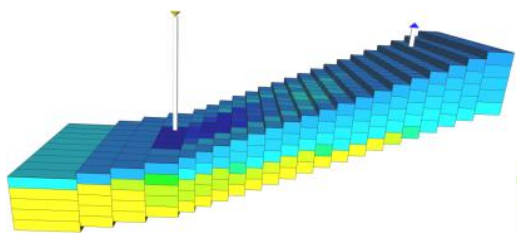

(a)

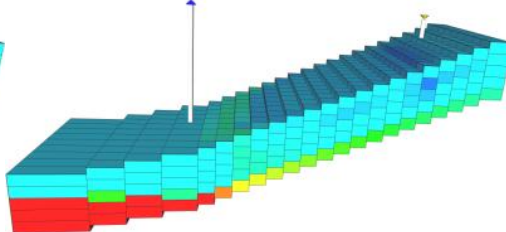

(b)

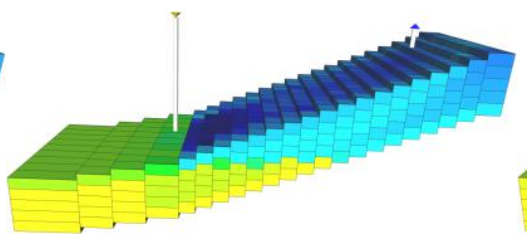

(b)

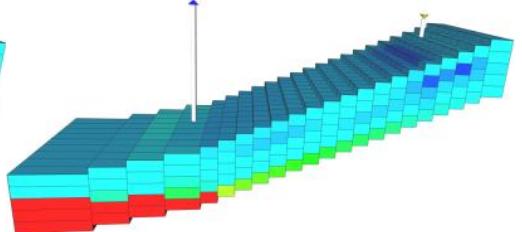

(c)

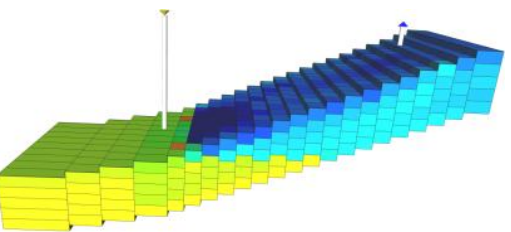

(c)

Figure 17. Water saturation distributions of air injection from updip (top) and downdip (bottom): (a) at 5 years, (b) at 10 years, (c) at 15 years. 


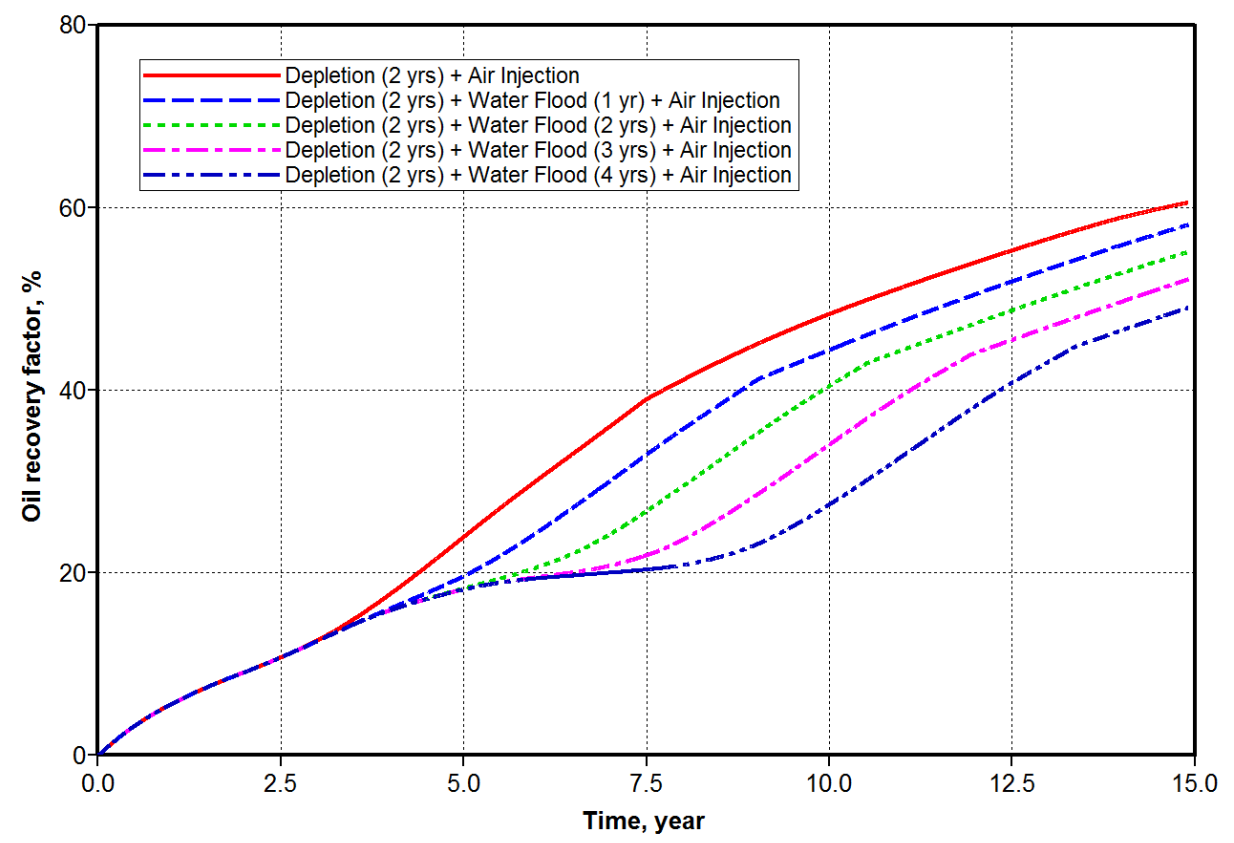

Figure 18. Effect of development scheme on oil recovery factor at different injection cases

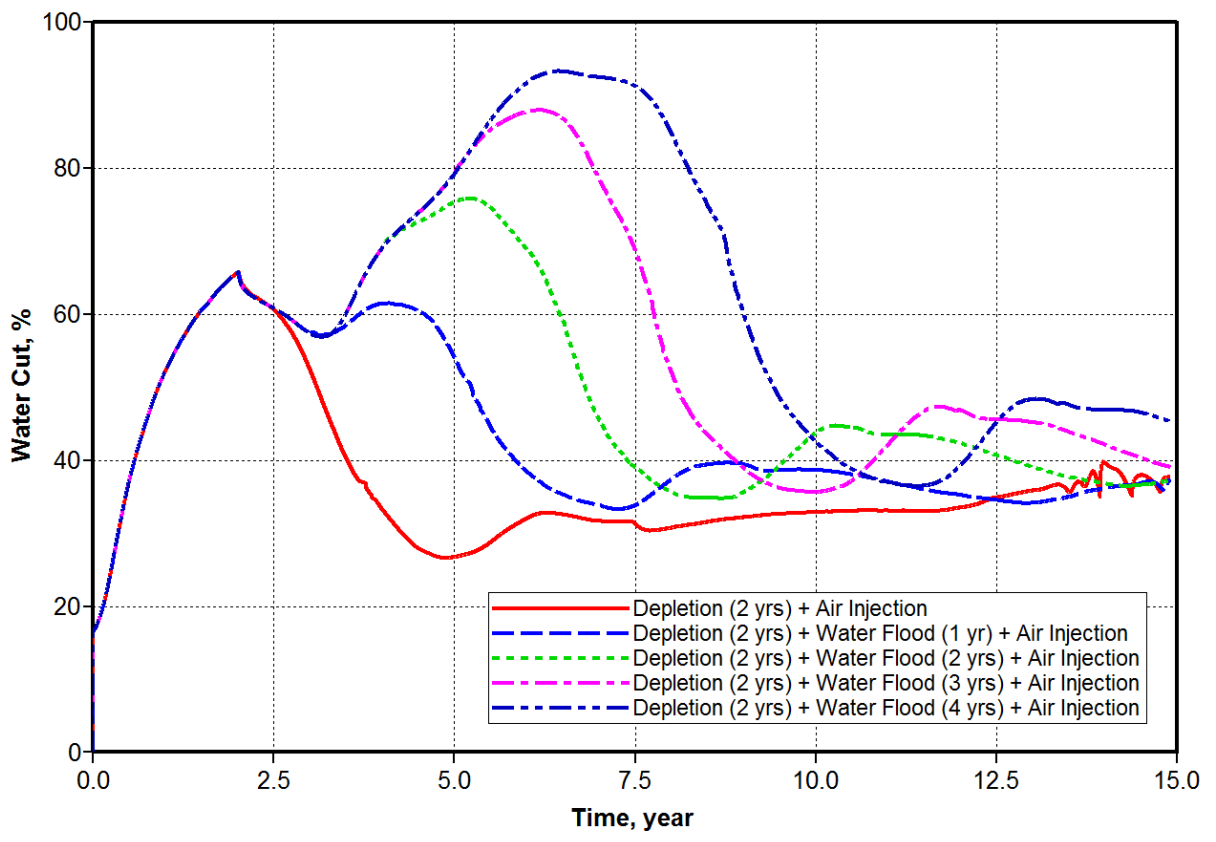

Figure 19. Effect of development scheme on water cut at different injection cases 